\title{
Application of instantaneous spectral analysis and acoustic impedance wedge modeling for imaging the thin beds and fluids of fluvial sand systems of Indus Basin, Pakistan
}

\author{
Muhammad Tayyab Naseer ${ }^{1, *}$ and Shazia Asim $^{1,2}$ \\ ${ }^{1}$ Department of Earth Sciences, Quaid-I-Azam University, Islamabad 44000, Pakistan. \\ ${ }^{2}$ Institute of Geophysics and Geomatics, China University of Geosciences, Wuhan, China. \\ *Corresponding author.e-mail: mtayyab.naseer1@gmail.com; muhammadtayyabnaseer@gmail.com
}

MS received 19 April 2017; revised 23 September 2017; accepted 6 February 2018;

published online 24 August 2018

Fluvial sand frameworks have magnificent oil and gas reservoirs far and wide. The reservoir sands are exceedingly compartmentalized by the broadened fault framework. So, to distinguish the thin beds of gas-bearing facies is an assessment for band-limited stratigraphic investigation. To conquest this issue, we execute the progressed seismic ascribe methods to the $3 \mathrm{D}$ seismic information of the Miano area of the Indus Basin, SW Pakistan. Apparatuses, for example, the seismic amplitude and coherence are discovered less exact for reservoir description. Sweetness analysis indicates the gas-bearing reservoir facies, which are compartmentalized by the NNW-SSE oriented normal fault system. Yet, the continuous wavelet transforms (CWT) of spectral decomposition (SD) separates the thick and thin sand beds of channel sand and point bars, which were not unsurprising utilizing the band-limited seismic properties. $22 \mathrm{~Hz}$ demonstrates the best amplitude tuning cube, which recognizes the profitable clastic (sand-filled barrier bars) sequences. The net-to-gross $(\mathrm{N} / \mathrm{G})$ examination uncovers the barrier bars as the chief hydrocarbon-bearing facies. 22 to $37 \mathrm{~Hz}$ frequencies confirm the occurrence of hydrocarbon sands. The acoustic impedance (AI) wedge model settles the thin beds of barrier bars sands, which are encased inside the shales, and affirm the suggestions for gas-bearing stratigraphic traps.

Keywords. Continuous wavelet transforms (CWT); reservoir characterization; seismic attributes; sweetness; thick and thin beds; fluvial sands.

\section{Introduction}

Channels and barrier bars loaded with a porous rock volume and encased in a non-porous matrix shields a standout amongst the most indispensable stratigraphic plays. Yet, comprehensive imaging of channels has a far more extensive effect. By methods of advanced and paleo-analogs, distinguishing the channels can be used to guide, model and portrayal of the paleo-depositional condition, and translate less clear potential regions, for example, sands, barrier bars and point bars, fans, and levees (Sahu and Saha 2014; Xiao et al. 2016; Naseer and Asim 2017a, b; Tayyab et al. 2017). These stratigraphic arrangements comprise a progression of hydrocarbon-bearing sands, for example, sand point bars, crevasse splays, and barrier bars, sand bodies together with the scattered mud filled over bank shale accumulation (Galloway and Hobday 1996). These potential sand reservoirs are enormously affected by the territorial NNW-SSE faults and the discontinuities. The portrayal of the 
thin beds of stratigraphic plays is one of the oil and gas investigation faces in the Miano gas field, Indus Basin, SW Pakistan. The reservoir implication for these sand organizations is that the point bars related to channel sands and the barrier bars are made out of the conceivable hydrocarbon compartments (Naseer and Asim 2017a). Subsequently, the detection and division of thick point and barrier bars clastics can be significant for future hydrocarbon investigation inside the Miano gas field, Pakistan.

The distinctiveness of the seismic data in nature is non-stationary. The tuning effect can create $1 / 4$ wavelengths and this is the threshold for any oil and gas-bearing reservoirs, which defines whether the reservoirs are above or below the tuning thickness after correlations with the real well evidence. Whereas, the ordinary seismic schemes cannot distinguish unit thickness at less than this value $(1 / 4)$. The conventional seismic tools cannot detect the leading fluvial hydrocarbonbearing reservoirs (fluvial channel fills and barrier bars sand deposits), which are overlain by the low-quality shales at this wavelength (Galloway and Hobday 1996; Chopra and Marfurt 2006). More imperatively, it is proven that tuning thickness shows the thickest reservoir interval, where the oil and gas-bearing straits exist. Therefore, it is a very vital and crucial step in characterizing the diversified plays within the clastic (fluvial and deltaic) and carbonates (lenticular lenses and barrier-reef, etc.) domain. Precautionary measures should be standardized before the application of complete range of reservoir characterization, i.e., structural, stratigraphic or their combinations.

The continuous wavelet transforms (CWT) has a lead over the other spectral decomposition schemes and the conventional seismic qualities that cannot deliver the broad evidence in signifying the whole stratigraphic play (Castagna et al. 2003; Castagna 2006; Naseer et al. 2015; Tayyab et al. 2017). This approach is more beneficial as compared to the full spectrum seismic gears by investigating the plentiful frequency volumes for depicting the stratigraphic reservoirs (Sinha et al. 2005). This decomposition established to be a dominant device in illuminating the subtle subsurface information that may lack in the seismic broadband. Over the last decades, numerous published works have discussed how this attribute can be used to differentiate both lateral and vertical lithologic and pore-fluid changes, estimating the temporal bed thickness, delineating the stratigraphic traps, and identifying the subtle frequency variations caused by hydrocarbons (Partyka et al. 1999; Castagna et al. 2003; Goloshubin et al. 2006; Chen et al. 2008; Puryear and Castagna 2008; Farfour et al. 2012).

Previously in the Indus Basin, seismic attributes and inversion technique were applied to delineate the reservoirs. Reservoir characterization is carried out for delineation of channel and barrier bar sands, but less emphasis was made for the detection of thin beds associated with the dominant point bars reservoir facies (Asim et al. 2016; Naseer and Asim 2017b; Tayyab and Asim 2017; Tayyab et al. 2017).

The present study is carried out for the recognition of dominant reservoir facies using the CWT and acoustic impedance (AI) wedge modeling tools on a 3D seismic data, which makes a novel approach as compared to the previous studies (Tayyab et al. 2017; Naseer and Asim 2017a; Asim et al. 2016; Tayyab and Asim 2017). This study deals resolving the gas-bearing beds of fluvial barrier bar, and their control on the overall reservoir quality in the Miano area, Indus Basin, SW Pakistan.

\section{Geology of the study area}

The research zone is the principal significant leap forward of worldwide, coordinated oil and gas organization situated in Vienna, named as OMV. These oil and gas groups seek into bunches for finds and concentrate oil and natural gas on four continents. OMV (Pakistan) underway the exploration activity of the Miano gas field in 1993 with the discovery of a natural gas reservoir called 'Miano' in the Thar Desert, District Sukkur (figure 1). The study area lies north to the Arabian Sea; the dominantly NS-trending Indus Basin is bounded by the Indian shield to the east, the Kohat Potwar Plateau to the north, and the fold and fault belts of the Sulaiman and Kirthar ranges to the west (Berger et al. 2009).

The foremost configurations of the Indus Platform are the rifting of Indian Plate from Gondwanaland (Jurassic or Early Cretaceous) which probably created NE-SW to N-S rift systems, isostatic uplift or ridge-push at the margins of the newly developed ocean, and probably caused uplift and eastwards tilting at the start of the Cretaceous (Kadri 1995). 


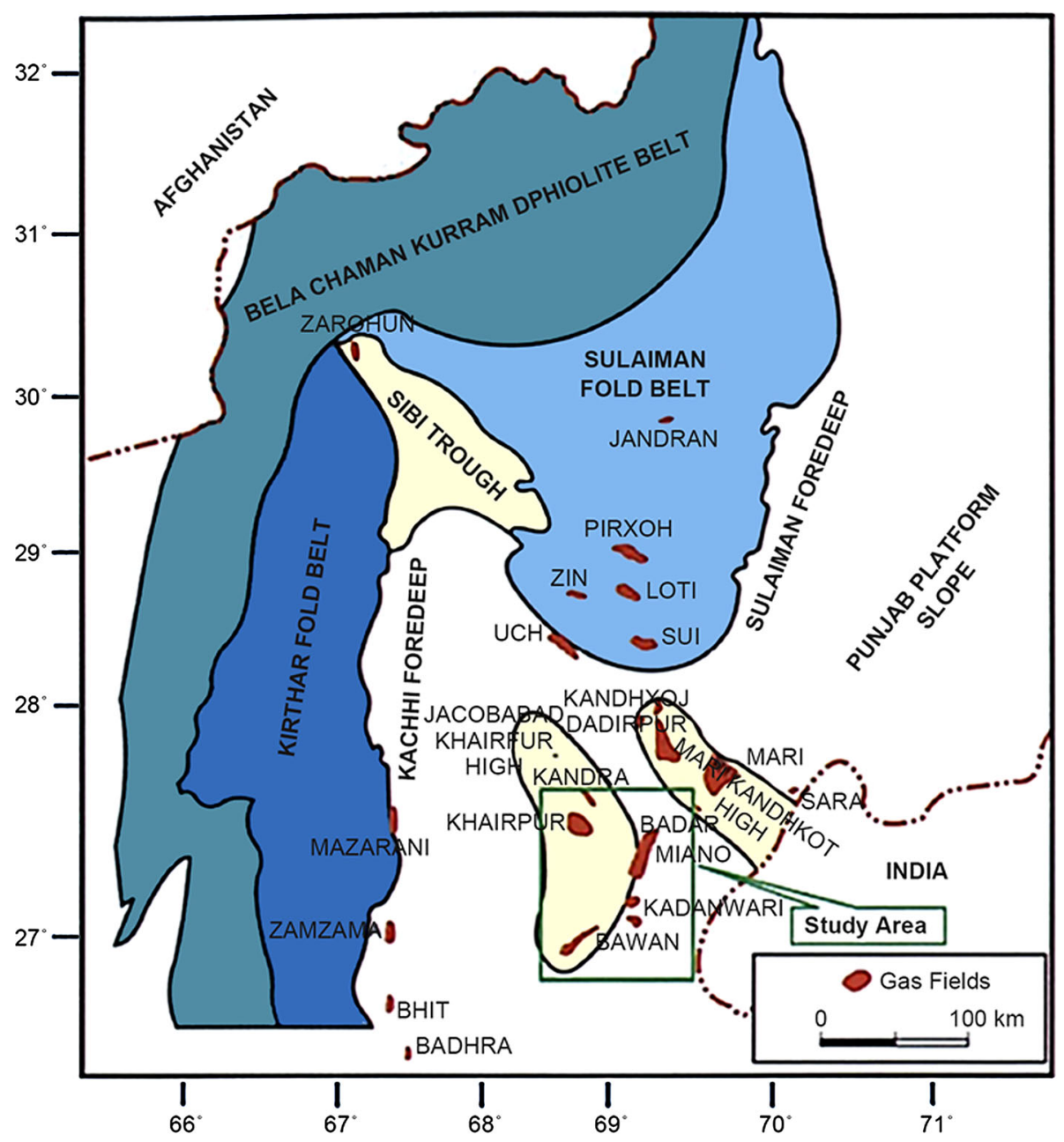

Figure 1. Generalized geology map of Indus Basin, showing the location of the Miano gas field in the Indus Basin.

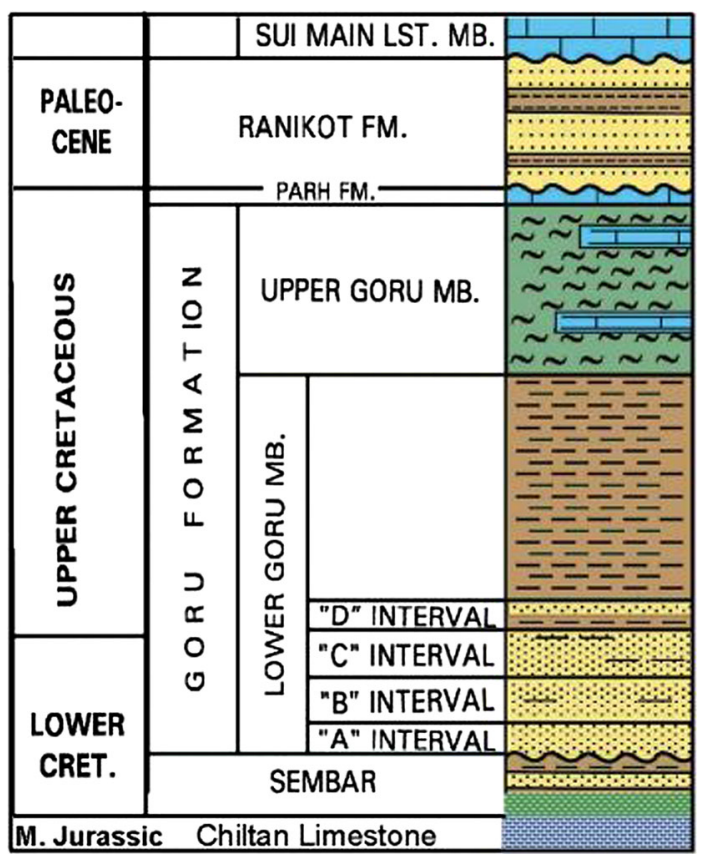

Figure 2. Generalized stratigraphic explanation showing the divisions of reservoir units within the Lower Goru Formation.

\subsection{Depositional settings and petroleum characteristics}

The Lower Goru Formation establishes as the chief reservoir with medium to coarse-grained sandstones. The depositional environment is varied; the shallow-marine, proximal wave-dominated delta system fluvial dominated deltaic, and barrier bar complex (Krois et al. 1998). Organic-rich shales within the Sembar Formation act as the source rock for most of the oil/gas field of the Lower and Middle Indus basins (Krois et al. 1998).

The lower fragments of the Lower Goru Formation have been producing the gas, which is further divided into four sand systems A, B, C, and D (figure 2). Pay sands, which are predominantly gas-saturated, reaching more than $30 \%$ porosity, are mostly encountered within mainly thin fluvialdeltaic sand systems. These sand systems exhibit anomalously high porosities and permeability at high temperatures and depths of $3000-3800 \mathrm{~m}$ (Ahmed et al. 2004). 
Table 1. Suite of well logs used for the present study.

\begin{tabular}{|c|c|c|c|c|c|c|}
\hline $\begin{array}{l}\text { Sl. } \\
\text { no. }\end{array}$ & Well name & Log suite & $\begin{array}{c}\text { Total } \\
\text { depth }(\mathrm{m})\end{array}$ & Status & Reservoir & $\begin{array}{l}\mathrm{KB} \\
(\mathrm{m})\end{array}$ \\
\hline 1. & Miano 01 & GR, LLD, LLS, RHOB, NPHI, DT4P & 4030 & Exploratory & Gas & 56 \\
\hline 2. & Miano 02 & GR, LLD, LLS, RHOB, NPHI, DT4P & 3548 & Appraisal & Gas/suspended & 63.5 \\
\hline 3. & Miano 03 & GR, LLD, LLS, RHOB, NPHI, DT4P & 3460 & Appraisal & Gas/suspended & 59.8 \\
\hline 4. & Miano 04 & GR, LLD, LLS, RHOB, NPHI, DT4P & 3527 & Development & Abandoned & 53.4 \\
\hline 5 . & Miano 05 & GR, LLD, LLS, RHOB, NPHI, DT4P & 3400 & Development & Gas & 65.8 \\
\hline 6. & Miano 06 & GR, LLD, LLS, RHOB, NPHI, DT4P & 3335 & Development & Suspended & 63.13 \\
\hline 7. & Miano 07 & GR, LLD, LLS, RHOB, NPHI, DT4P & 3429 & Development & Gas & 64.75 \\
\hline 8. & Miano 08 & GR, LLD, LLS, RHOB, NPHI, DT4P & 3385 & Development & Gas & 57.62 \\
\hline 9. & Miano 09 & GR, LLD, LLS, RHOB, NPHI, DT4P & 3610 & Development & Gas & 80 \\
\hline 10. & Miano 10 & GR, LLD, LLS, RHOB, NPHI, DT4P & 3610 & Development & Gas & 77 \\
\hline
\end{tabular}

\section{Dataset}

These seismic data are composed of a 3D seismic survey acquired in 1999 for the Miano gas field. The principal objective is to image deep gas reservoirs at depths of $\sim 3000-3500 \mathrm{~m}$. The quality of seismic data is excellent for reservoir characterization. A complete suite of well logs data is available for 10 wells in the Miano gas field. The present study uses the gamma-ray (GR) (API), resistivity (LLD, LLS) (Ohm-m), bulk density (RHOB) (g/c.c), neutronporosity (NPHI) (in fractions), and sonic-porosity (DT4P) (micro sec/ft) of Miano 05 and Miano 07 (table 1).

\section{Methods}

\subsection{Seismic attributes for reservoir description}

Advanced seismic attributes technology is useful in the qualitative and quantitative reservoir characterization. These seismic tools can be helpful for detecting and delineating the fluvial-deltaic depositional features of hydrocarbon interest. Some attributes, such as relative acoustic impedance and coherence volume, are directly sensitive to changes in seismic amplitude (Chopra and Marfurt 2005). Common usage of seismic attributes comprises stratigraphic features detection and prediction physical properties of the formation of interest (Radovich and Oliveros 1998).

\subsubsection{Coherency attribute}

Because the coherency measurements in three dimensions represent the trace-to-trace similarity, they produce interpretable changes (Chopra et al. 2011). Similar traces are mapped with high coherence coefficients and discontinuities, such as regional discontinuities and fluvial-deltaic channellike features (channels, barrier bars, and incisedvalley fills) and subtle stratigraphic features have low coefficients. The low coherence values delineate the stratigraphic discontinuities.

\subsubsection{Sweetness attribute}

Mathematically, the sweetness volume is calculated by dividing the reflection strength (or instantaneous amplitude envelope) by the square root of instantaneous frequency (Radovich and Oliveros 1998).

\subsection{Spectral decomposition}

\subsubsection{Basics of spectral decomposition}

The basis of the spectral decomposition practice is the thin bed tuning effect. It occurs when traces from the top and bottom layers have a constructive interface. In this effect, the thin beds have a distinct response of frequency. It will be defined as a thin bed if the thickness of the reservoir is greater or equal to $1 / 4$ wavelength.

Below 1/4 of the dominant period, the thin beds cannot be detected. Spectral decomposition is used from the inverse relationship between the wavelength and frequency for thin beds recognition, i.e., with increasing frequency, wavelength decreases, and vice versa.

\subsubsection{Mechanism for stratigraphic reservoir characterization}

It converts seismic data from the time domain to the frequency domain. One basic concept could 
be both examining data in the time domain at different frequencies and compare the response to provide significant insight for stratigraphic reservoir characterization.

\subsubsection{The CWT tool}

CWT is the most robust method among all spectral decomposition that is routinely applied in the petroleum industry (Castagna 2006; Tayyab et al. 2017; Naseer and Asim 2017a; Tayyab and Asim 2017). In this study, CWT is used to provide stratigraphic characteristic and shows the thickness distribution of stratigraphic features.

\subsubsection{Processing of CWT attribute}

The octave band scale is selected for processing of spectral decomposition attributes in order to avoid the ringing effects of bad signals, which can enhance reservoir characterizations in locating the hydrocarbon-dominated thick sand zones.

\subsubsection{Applications of CWT}

Spectral decomposition has been used to highlight channels (Partyka et al. 1999; Naseer and Asim 2017a; Tayyab and Asim 2017) and their thickness distribution in both quality and modality. The spectral decomposition images are complementary to coherence and edge-detection attributes. This tool is sensitive to channel thickness rather than to lateral changes in seismic waveform or amplitude. Spectral decomposition analysis can be conducted within a time window analysis following a picked stratigraphic horizon, thereby generating a suite of constant frequency spectral amplitude maps. There is a strong correlation between channel thickness and spectral amplitude (Laughlin et al. 2003).

\subsection{Comparison between various seismic attributes}

Seismic attributes such as the coherence, which is sensitive to the edges of stratigraphic events (such as channels, barrier bars, and incised-valley), are among the most popular means of mapping reservoir boundaries. Although these attributes can easily detect channel edges, they cannot indicate the channel's thickness, and when the channels become very thin (well below $1 / 4$ wavelength), their waveform becomes constant; as a result, coherence attributes, which are measured based on waveform shape, cannot detect the channel (Chopra and
Marfurt 2007). So, to overcome this exploration concern, the CWT technique does not attach to preselecting the time window length and does not have fixed time-frequency resolution for the seismic data analysis. This method takes a lead over the conventional seismic data by testing the multiple frequency volumes for stratigraphic reservoir characterization without any bandwidth limitation (Sinha et al. 2005; Tayyab et al. 2017; Naseer and Asim 2017a). More importantly, when the bandwidth processing is applied to the amplitude-based seismic attributes, the true lithology, thickness, and porosity effects can also be predicted, in-spite of the unavailability of the seismic data inversion platforms tools. These observations can be visualized when the processing of designed bandwidth are experienced on the full spectrum amplitude-based seismic attributes.

\subsection{Petrophysical analysis}

The petrophysical strategy started in the 1950s, where reservoir qualities were steadfast utilizing logs, cores, and well appraisals. The second gathering established mostly on geologic similitudes included the thought between wells. The simple practice enhanced between well expectation, however distinguishing the correct simple regularly demonstrated troublesome, particularly in basic and stratigraphically complex settings. A multidisciplinary approach, the third gathering, endeavours to incorporate all accessible geologic, engineering, and geophysical information alongside present-day likelihood and hazard investigation systems to create a superior reservoir portrayal (Evans 1996; Asim et al. 2016).

\section{Results and discussions}

\subsection{Synthetic modeling}

The zone of research is defined between the time windows of $\sim 1.14$ to $1.7 \mathrm{~s}$, which is composed of fluvial-deltaic sediments of Early-to-Late Cretaceous age. Seismic data interpretation is initially started by convolving the extracted wavelet (figure 3a) with the reflectivity series to obtain the final synthetic seismic seismogram. The peak frequency within the reservoir zone is $\sim 22 \mathrm{~Hz}$ (figure $3 b$ ).

The synthetic modeling is done by convolution of the wavelet, and to correlate the sand character 

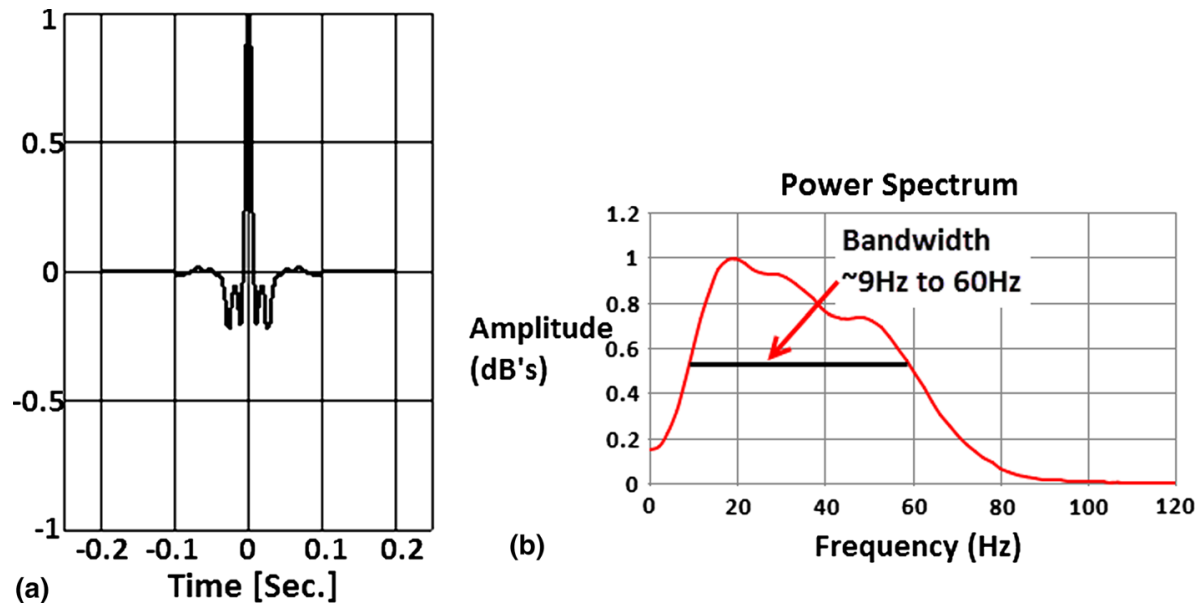

Figure 3. (a) Time representation of the seismic wavelet extracted from the conventional seismic amplitude volume. (b) The computed frequency spectrum shows the bandwidth of the study zone.

\begin{tabular}{|c|c|c|c|c|c|c|c|}
\hline $\begin{array}{l}\text { Time[Sec.] } \\
\text { /Depth[m] } \\
\text { Miano } 06\end{array}$ & $\begin{array}{c}\mathrm{Al} \\
\mathrm{kg} / \mathrm{cc}^{*} \mathrm{~m} / \mathrm{sec} \\
30000 \quad 40000\end{array}$ & $-0.4 \quad-0.1 \quad 0.2$ & $\begin{array}{c}\text { Extracted } \\
\text { wavelet } \\
\text { Miano } 06\end{array}$ & $\begin{array}{l}\text { GR [API] } \\
50100150200\end{array}$ & $\begin{array}{c}\text { Miano 3D } \\
\text { Trace } \\
r=0.310\end{array}$ & $\begin{array}{c}\text { Synthetic [-] } \\
\text { Extracted } \\
\text { wavelet } \\
13200\end{array}$ & $\begin{array}{c}\text { Borehole } \\
\text { Formation } \\
\text { Tops }\end{array}$ \\
\hline $\begin{array}{l}1.06=1825 \\
1900\end{array}$ & 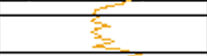 & & & & 335 & 3333 & \\
\hline 1.14 & $=$ & 表 & & 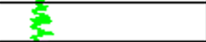 & दोडst & 33 & Ton of \\
\hline $118=2050$ & $-3^{3}$ & $1=$ & & 童 & sis & 330 & $1000 T$ \\
\hline $122=2125$ & $=3$ & 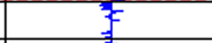 & & 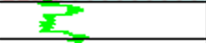 & SEL & 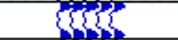 & Lower \\
\hline $1.22=2200$ & -5 & $E$ & & $\Rightarrow$ & $=8$ & 515 & Goru \\
\hline $1.26=2275$ & $x=$ & 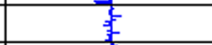 & & 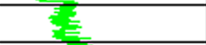 & $+\infty$ & & \\
\hline $1.30=2350$ & 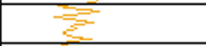 & 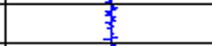 & & $=$ & SO & Bis & \\
\hline $1.34=2425$ & 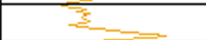 & 3 & & 5 & 353 & 335 & \\
\hline $1.38=2500$ & $\Rightarrow$ & $=$ & & $=1$ & हst & 365 & \\
\hline $1.42=2575$ & $=$ & $=$ & & $\Rightarrow$ & 3535 & 383 & \\
\hline $1.46=2650$ & $=$ & 素 & & $=\frac{7}{5}$ & 385 & 3.t.3. & \\
\hline 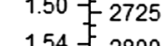 & $=$ & 表 & & $=$ & 33 & 3333 & \\
\hline $1.54=2800$ & $=$ & 策 & & $\Rightarrow$ & ?3!3? & 333 & \\
\hline $1.58=2875$ & -3 & 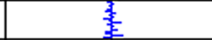 & & $z=$ & 355 & PRP & \\
\hline $1.02=2950$ & $x=$ & 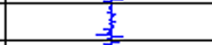 & & $\Rightarrow=$ & 353 & उदि & \\
\hline $170=3100$ & $=$ & 标 & & $=$ & 331 & 3SBS & \\
\hline $1.10=3175$ & $\Rightarrow=----1$ & ------奉- & & $=5$ & --53 & & Sand 1 \\
\hline & $=$ & F & & $\Rightarrow$ & मीदर & 335 & \\
\hline
\end{tabular}

Figure 4. Well to seismic tie showing the correlation of reservoir characteristic (acoustic impedance) obtained from seismic and well data and the interpreted horizons, i.e., top of Lower Goru and Sand 1 (red horizontal dotted lines). The orange curve shows the acoustic impedance log, which is generated at well location. The blue positive and negative impulses are the discrete events of reflection coefficients. The green curve shows the GR log. The red wiggles are traces extracted from 3D seismic data, while the blue traces show the trace extracted from well.

obtained from well logs with the seismic data. One of the well to seismic overlay is shown in figure 4.

\subsection{Seismic visualization and horizon interpretations}

Figure 5 shows the interpreted horizons and the fault system. Two key horizons, which include the top of Lower Goru and the B-Reservoir (Sand
1), are picked and interpolated to obtain the continuous surface mapping through the attribute extraction procedure to characterize the incisedvalley system. The gas-bearing sands have a low acoustic impedance than the surrounding shales (Naseer and Asim 2017a). Since the transgressive system tracts have thinnest reservoirs in terms of geology, and therefore, the upper or shallow zone is generally assumed as the erosional sediments where the seismic amplitudes are very 


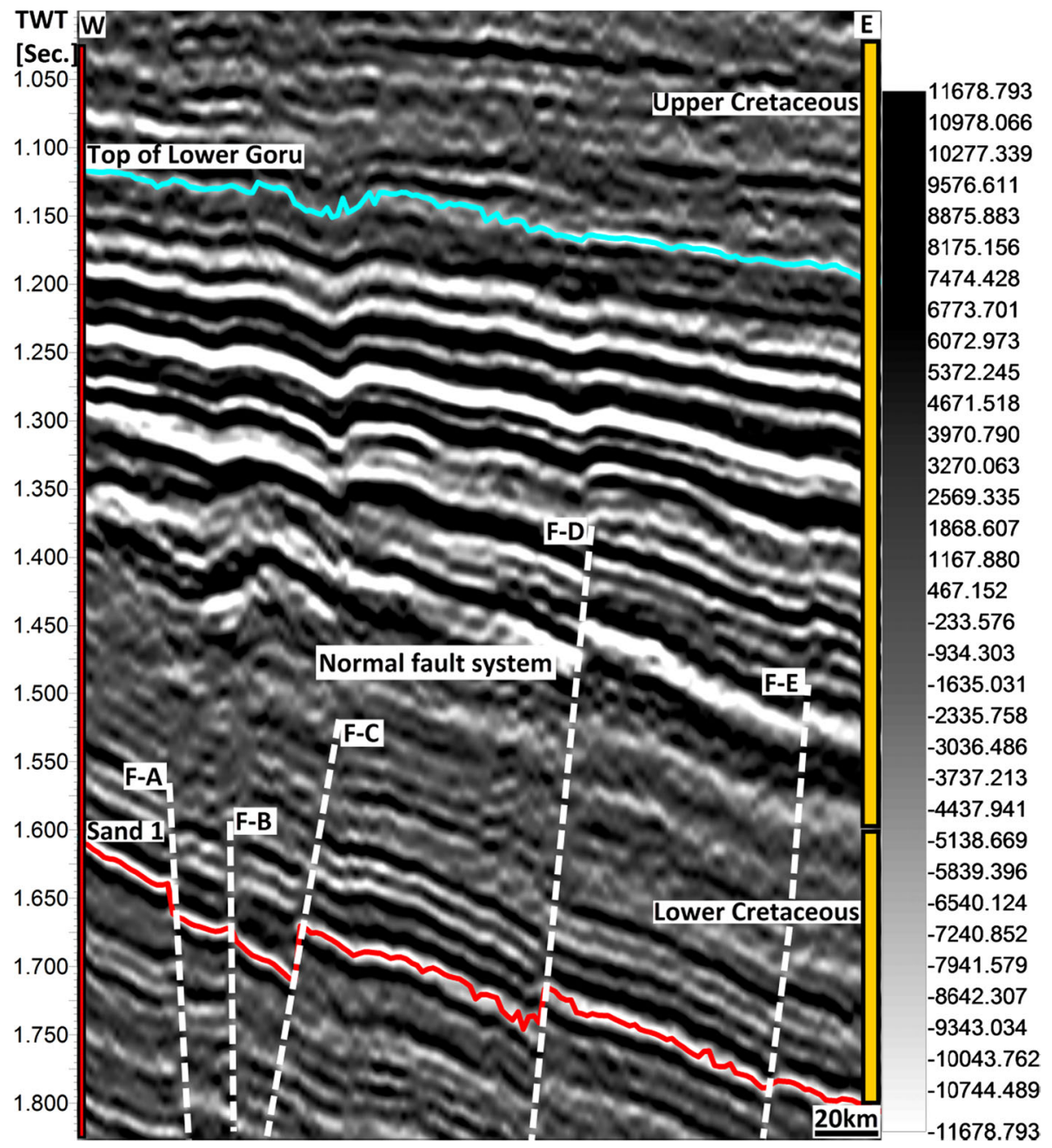

Figure 5. Vertical seismic transects showing the interpreted horizons (cyan and red colour) and fault system (white dotted line). The zone of interest is shown by red vertical bar, while the division of Cretaceous Era is shown by orange colour.

dim between the time window of 1.4 and $1.6 \mathrm{~s}$. Moreover, the channels have eroded the subsurface regimes, resulting into the development of incisedvalleys, where the thickest reservoir prospect exist. Therefore, the oil and gas-bearing prospect is marked by Sand 1 strait. The Sand 1 is marked within the trough of the conventional seismic data section. There are two zones, which includes the Upper Cretaceous (1.05-1.5 s) and the Lower Cretaceous (1.59-1.82 s). Both the zones have uniform sedimentation rate with very good stratigraphic continuity, and hence, it is inferred that the amplitudes are preserved, and the porous sandstone reservoirs are present within these two zones (Tayyab and Asim 2017). However, the gas-bearing intervals are proven in the Lower Cretaceous (Naseer and Asim 2017a). Therefore, the zone that composed of Lower Cretaceous is preferred in the present study, where the amplitude attenuation, synthetic wedge modeling, and the petrophysical analyses are preformed (figures 11 $-15)$. On the other side, the zone between $\sim 1.5$ and $1.58 \mathrm{~s}$ shows the less continuity and the poor reflection data, and hence, it is inferred as the non-porous transgressive sands, which are acting as a seal configuration within the Miano gas field (Krois et al. 1998).

As far as the structural inference is concerned, there are five faults, which are interpreted on the conventional seismic data; which includes the F-A, F-B, F-C, F-D and F-E. These faults are interpreted as the normal fault system, which bound the reservoir sands within the fluvial system of Miano gas field (Krois et al. 1998).

\subsection{Seismic amplitude and relative acoustic impedance analysis}

Figure 6 shows the horizon slices of amplitudebased seismic attributes to have reconnaissance 

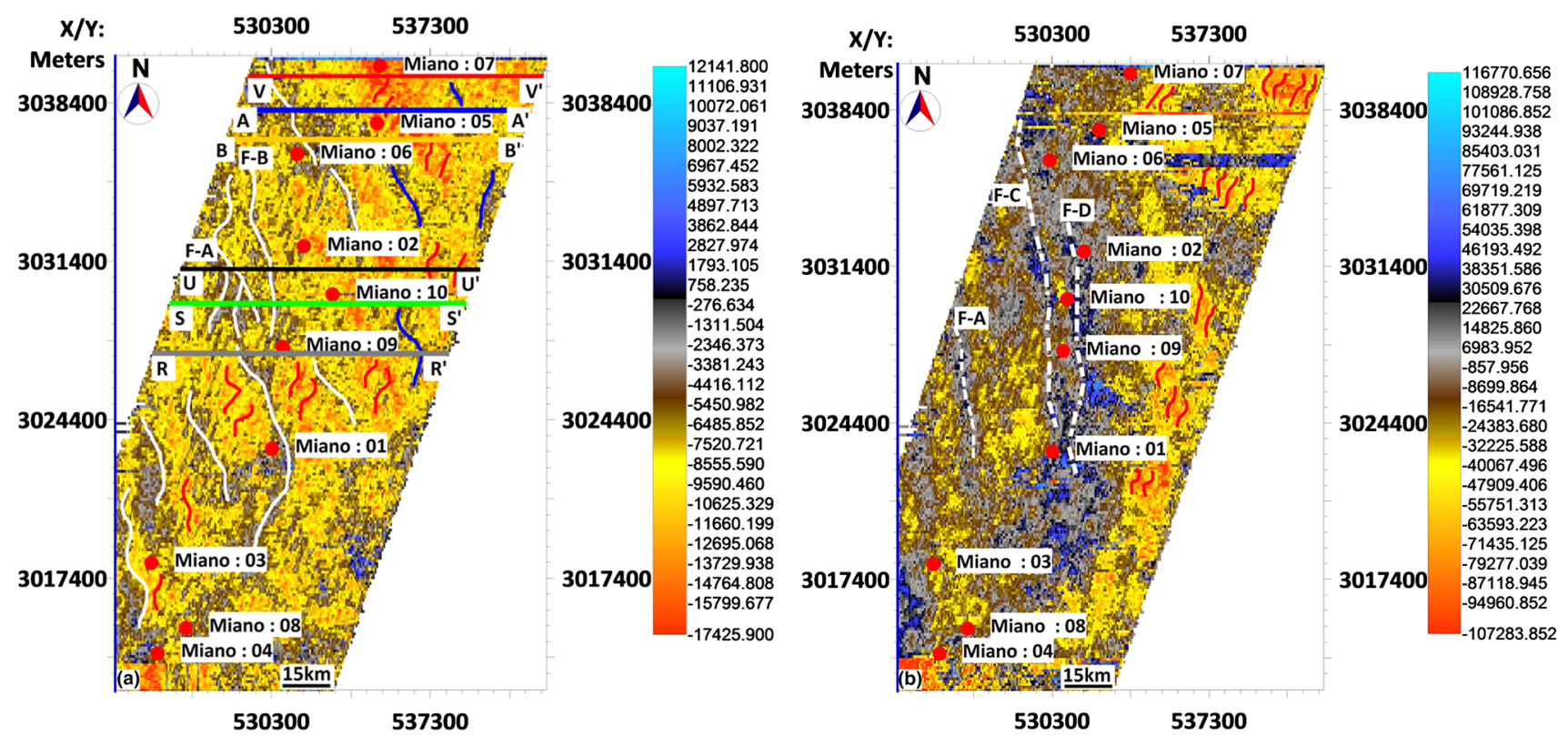

Figure 6. Horizon slices of Sand 1. (a) Seismic amplitude and (b) relative acoustic impedance, showing the regional distribution of faults (white dotted lines), fractures (red curvilinear lines), and the reservoir sands (red colour). The $\mathrm{AA}^{\prime}$ and $\mathrm{BB}^{\prime}$ cross sections shows the location which are used to correlate the fluvial channel sands and point bars in figure 7 . UU shows the location which are used for correlating the regional faults in figure $8 . \mathrm{RR}^{\prime}$ and $\mathrm{SS}^{\prime}$ show cross sections used for the correlation of barrier bars and incised-valley fills in figure $11 . \mathrm{VV}^{\prime}$ shows the cross section, where the synthetic wedge model is made for Miano 07 in figure 16.

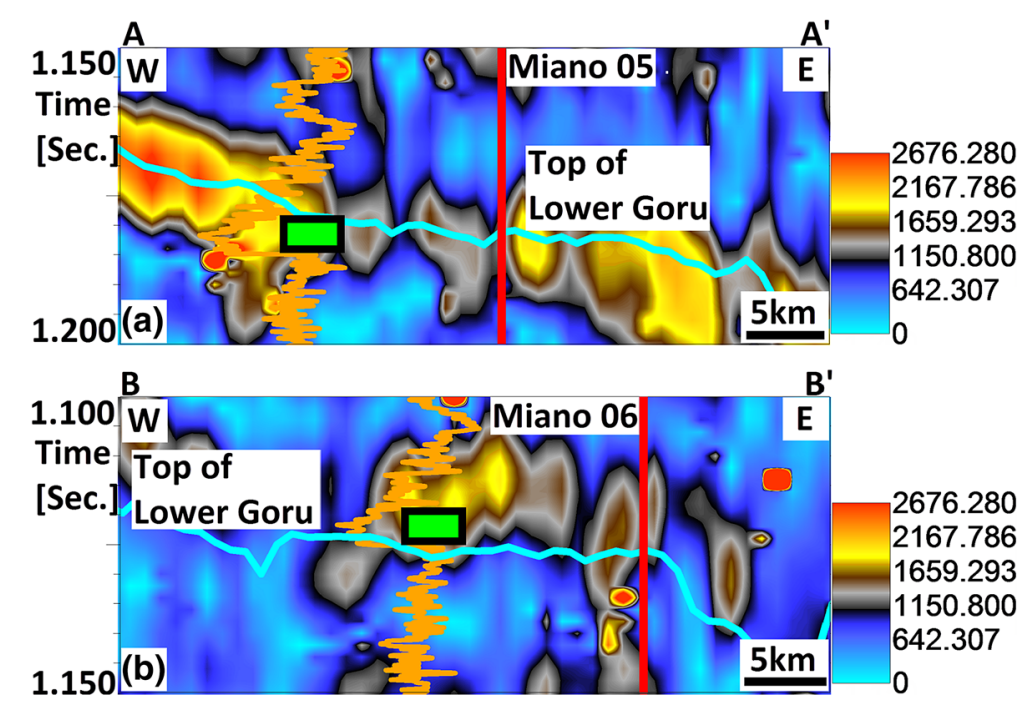

Figure 7. Sweetness volumes along the represented wells. (a) Miano 05 and (b) Miano 06, showing the lithology correlation of fluvial point bars and channel sands (green horizontal bar).

imaging for the deeper productive reservoir zones. Figure 6(a) shows the seismic amplitude horizon slice of Sand 1. High values are shown by the blue colour, while the lower ones are shown by orange colour. Massive reservoir sands with bright negative amplitudes are seen in the northern and the central parts of the study area. Moreover, the amplitudes horizon slice delineates the dense fracture network (red curvilinear lines) regional faults (white curvilinear lines); which includes the
F-A, F-B and F-C. The shallow reserve zone is dominantly influenced by the fluvial sediment influx. The fining upward GR log cycle is interpreted as the fluvial channel and point bars sand geometries. Therefore, the high values of sweetness attribute confirm the presence of possible gas-bearing reservoir (channel fills and point bars) sands. Miano 05 and Miano 06 falling within these zones correlate the interpretation (figure $7 \mathrm{a}$ and $\mathrm{b}$ ). Hence, these reserve sands are interpreted as the 


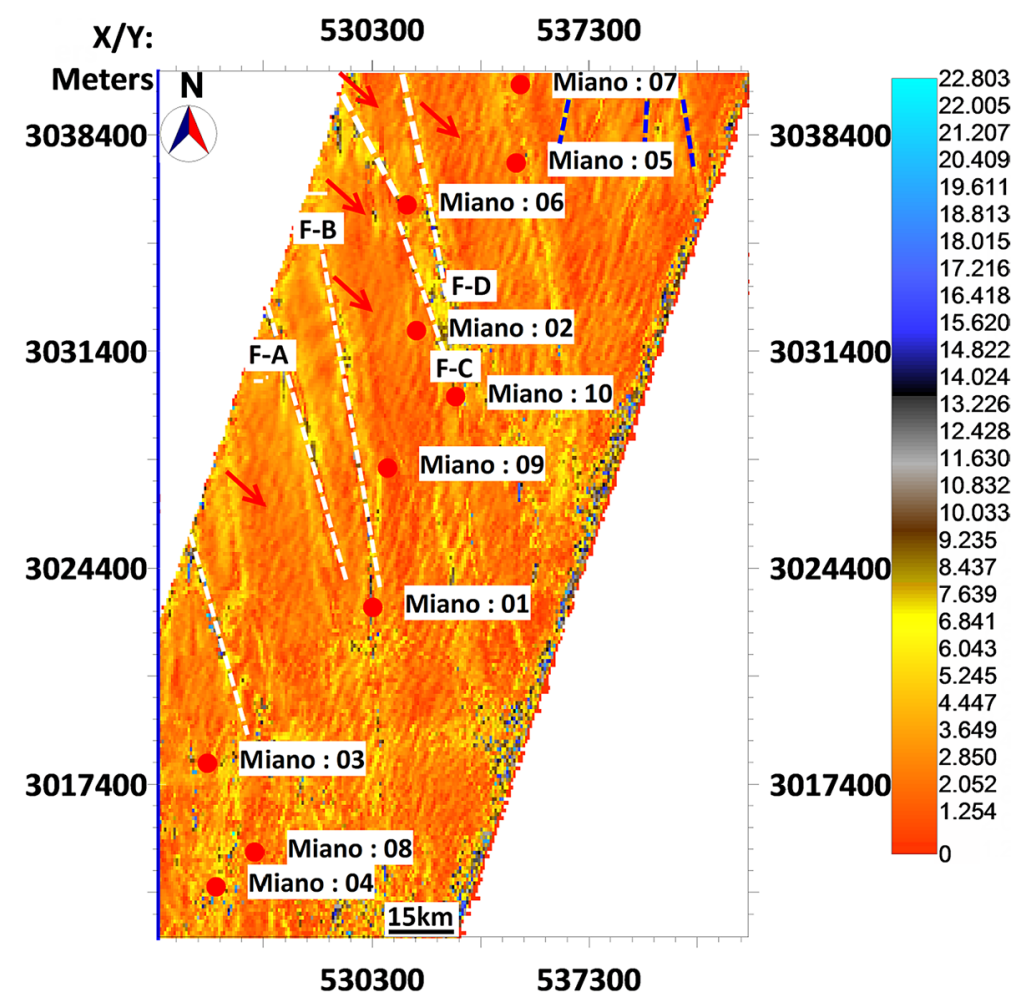

Figure 8. Coherency horizon slice of Sand 1, showing the marked regional faults (white dotted lines), incised-valley fills (red arrows) and discontinuities (blue dotted line).

channel fills and point bars sand deposits (Krois et al. 1998; Naseer and Asim 2017a; Tayyab and Asim 2017). GR log cannot be used as a direct hydrocarbon indicator. However, the reservoir zone can be accurately marked. Therefore, it is suggested to plan for new well logging to have a complete suite of well logs, available at this shallow zone for extraction of hydrocarbons.

Amplitude emphasizing such as the relative acoustic impedance has established to be a tremendous toolkit for inferring the direct oil and gas events. This characteristic of seismic data has been successfully applied in the detection of sand deposits within the heterogeneous fluvial depositional systems (Singavarapu et al. 2014). Figure 6(b) shows the relative acoustic impedance (RAI) horizon slice of Sand 1, which delineates the three faults (white dotted lines); which includes F-A, F-C and F-D. However, RAI shows the bright negative amplitudes within the dense fracture network (red curvilinear lines) on the eastern part of the study area. Since the eastern part of Miano gas field is inferred as the shale dominated water-bearing zones, it is interpreted as non-productive zone (Naseer and Asim 2017a). The tuning effects due to water-bearing sediments might have caused to illuminate these bright negative amplitudes (Lynch and Lines 2004; Naseer and Asim 2017b).

Figure 6(a) shows the curvilinear fault expressions as compared to the RAI, which shows the linear fault geometries figure 6(b). Since the incised-valley of Miano gas field experiences the gas production from the barrier bar and valley fills, it experiences the linear fault patterns. Therefore, based on these observations, the RAI proves a better tool for reconnaissance study as compared to the seismic amplitude horizon slice.

\subsubsection{Detection of fluvial sand-filled channels and point bars deposits}

Sweetness attributes have been successfully applied to delineate the fluvial sand deposits within the Indus Basin (Tayyab and Asim 2017). Figure 7 shows the sweetness volumes, which are computed at Miano 05 and Miano 06. These wells surround the fluvial facies (green horizontal bars), which are identified in the seismic amplitude horizon slice (figure 6a). The flat base with fining upward GR log expressions is interpreted as the fluvial channels and point bars sands (green horizontal bars), and hence, confirms the presence of channel sands and point bars deposits at the Upper 

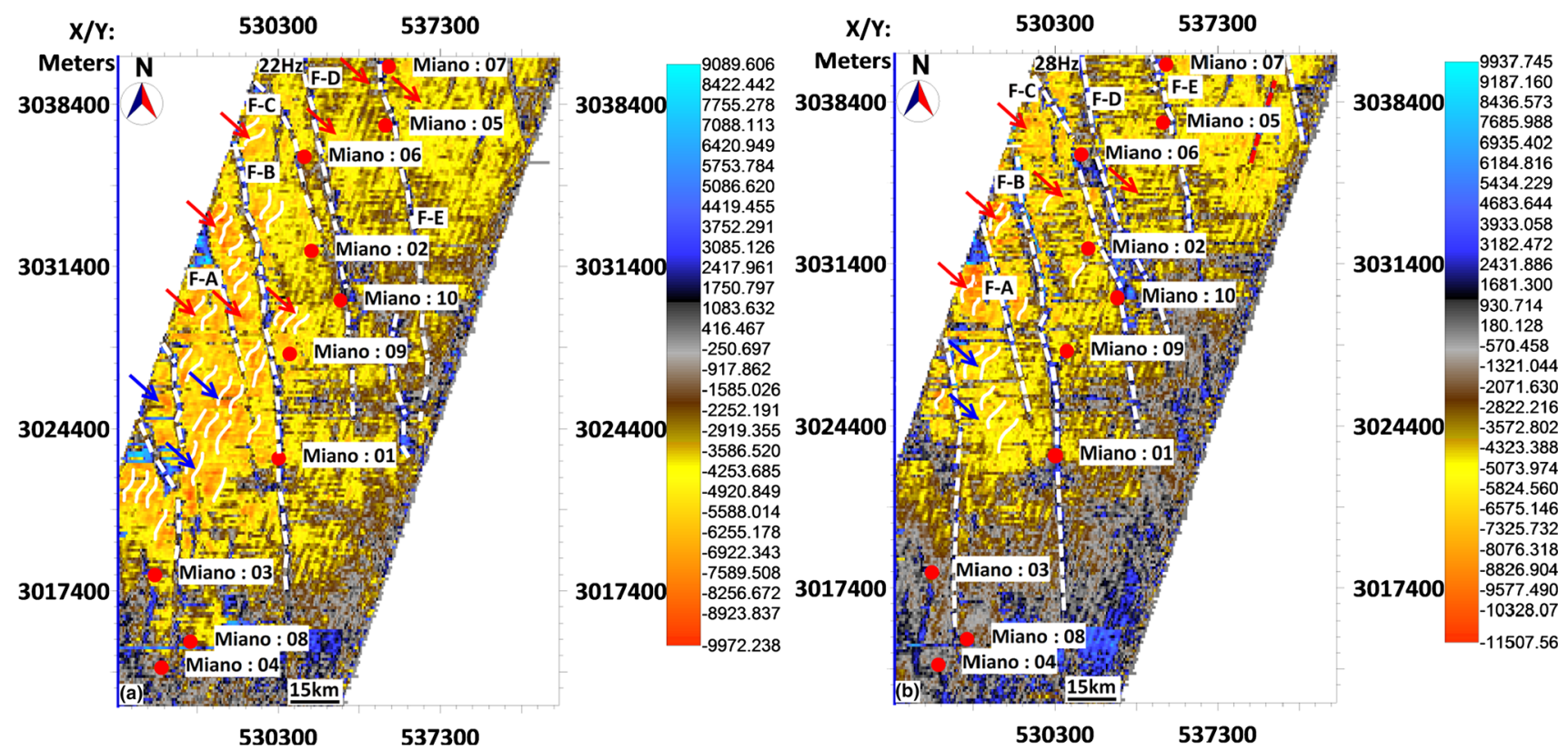

Figure 9. CWT horizon slices of Sand 1. (a) $22 \mathrm{~Hz}$ and (b) $28 \mathrm{~Hz}$, showing the interpreted faults (white dotted lines), fractures (white curvilinear lines) and reservoir sands (orange colour zones).

Cretaceous zone of the Goru Formation (Rider 1986; Tayyab and Asim 2017); Therefore, at the base of GR (API), the permeability will also be high as porosity. However, Miano 05 shows higher sweetness amplitudes (figure 7a), while Miano 06 shows lower sweetness amplitudes. It is also evident from table 1, which shows the status of gas producing sand occurred within Miano 05, and confirms the present observations. Consequently, the Upper Cretaceous zone of the Goru reservoirs inferred as the fluvial environment; which includes channel and point bars sand deposits (figure 5).

\subsection{Seismic coherency mapping and discussions}

Figure 8 shows the coherency horizon slice of Sand 1. Colour conventions are same as that of figure 6 . This horizon slice is generated in the Lower Cretaceous, which is the proven hydrocarbon-bearing zone (Krois et al. 1998). Coherency is a proven conventional tool for delineation of fault system and the edges of incised-valley system (Partyka et al. 1999). So, the horizon slice of Sand 1 shows an eye-catching image of the complete fault system. These faults are NNW-SSE oriented, and hence, are interpreted as the normal fault system, which compartmentalizes the incised-valley sand fills (Krois et al. 1998). The high coherences are interpreted as the locations for the stratigraphic features, i.e., coarse-grained sand-filled barrier bars and channel fill (Partyka et al. 1999). Hence, there are some patches, which show the sand fills (red arrows) and barrier bars (blue arrows) locations. Moreover, local scaled discontinuities (blue dotted lines) are also seen in the NE part of the study area. To probe the better stratigraphic interpretation, it is imperative to process the conventional seismic data to achieve the frequency-based amplitude tuning cubes (figure 9).

Based on the observations of full spectrum seismic attributes, the faults and the reservoir sands imaged by these attributes do not provide reliable interpretation (figures 6 and 8). Therefore, it is significant to decompose the band-limited seismic amplitude into its frequency domain to prove robust and authenticity probes for the detection of gas-bearing lithologies (thin beds) and the reservoir architecture (figure 9).

\subsection{Amplitude-based CWT attributes imaging and discussions}

Figure 9 shows the CWT horizon slices of Sand 1 , which are generated at $1644 \mathrm{~ms}$. Colour conventions are same as the coherency attribute map (figure 8). Figure $9(\mathrm{a})$ is the amplitude map of the $22 \mathrm{~Hz}$ cube. On the other hand, figure $9(\mathrm{~b})$ shows the amplitude map of $28 \mathrm{~Hz}$ tuning cube. Since the $22 \mathrm{~Hz}$ is the dominant frequency of the reservoir zone, the $22 \mathrm{~Hz}$ is considered 


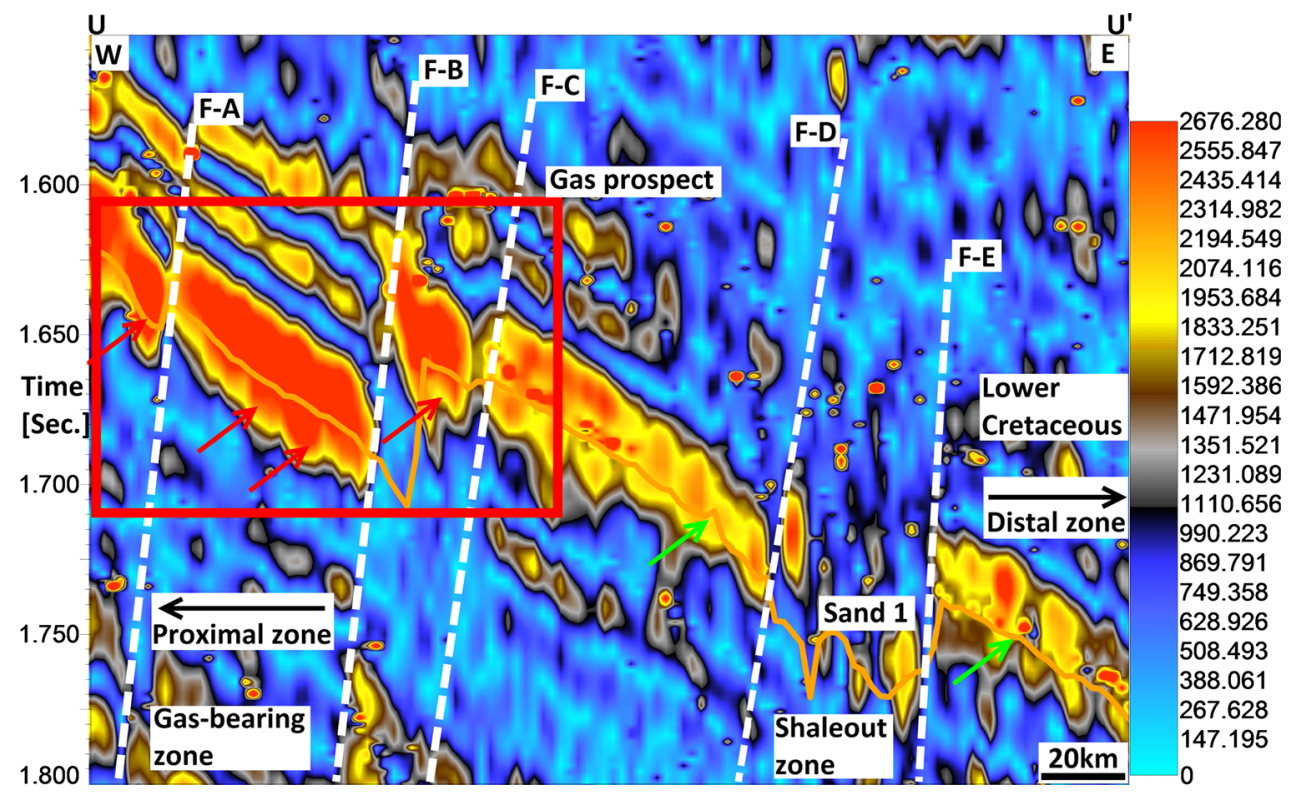

Figure 10. Sweetness volume computed between Miano 02 and Miano 10, showing the interpreted reservoir and the fault system (white-dashed lines). The gas prospect is shown by the red arrows within red rectangle, while the shale out zone is shown by the green arrows.

as the tuning thickness of the incised-valley reservoirs (figure $3 \mathrm{~b}$ ). The most reliable factor to approve the authentic interpretation of the reservoir sands is that CWT provides the frequency slices without band limitation. These horizon slices are generated within the defined spectra (figure $3 b$ ).

The $22 \mathrm{~Hz}$ tuning cube diligently illuminates the reservoir sands and regional fault system (white dotted lines), which shows the linear fault patterns (figure 9a). These channel boundaries are characterized as the NNW-SSE oriented normal faults, which result in the formation of incised-valley system (Krois et al. 1998). There are two types of clastic reservoirs, which includes the incised-valley fills (red arrows) and the barrier bar sand deposits (blue arrows) within the dense fracture network (white curvilinear lines), and imaged by $22 \mathrm{~Hz}$ horizon slice (figure 9a). Therefore, these fractures might have played a vital role in the upward migration and trapping of the gas-bearing sands. The productive reservoirs of Miano gas fields are bonded by the transgressed sands (Krois et al. 1998). These sand deposits are bounded by the regionally distributed NNW-SSE faults, making as excellent structural/stratigraphic trapping configurations. These reservoirs are excellently tuned $22 \mathrm{~Hz}$, which is inferred as the thin-bedded fluvial packages with gas-bearing stratigraphy within the Miano gas field (Krois et al. 1998; Naseer and Asim 2017a). The exploration and production companies are in search or the remaining stratigraphic traps within the Indus Basin (Kadri 1995). Consequently, by drilling more development at the top of Sand 1 horizon, where the incisedvalley fills and the barrier bar sands are detected, and hence, these sediments would be beneficial for future reservoir development.

$28 \mathrm{~Hz}$ tuning cube also delineates the regional fault system (figure 9a). However, the amplitudes are getting low as compared to the $22 \mathrm{~Hz}$ tuning slice (figure 9a). The dimming of high amplitudes is interpreted as the background shale intercalations within the gas-bearing sands, which have caused the amplitudes to attenuate within the productive zone (Naseer and Asim 2017a). Sweetness amplitudes correlate the identified faults and the reservoir sands (figure 10).

\subsubsection{Faults correlation and thick sand indications}

Figure 10 shows the sweetness computed between Miano 02 and Miano 10, correlates the interpreted faults, which are illuminated by the $22 \mathrm{~Hz}$ and $28 \mathrm{~Hz}$ amplitude tuning cubes. High amplitudes are seen below the Sand 1 horizon (red arrows). These are the locations, where the barrier bar and the incised-valley fills are tuned at the $22 \mathrm{~Hz}$ amplitude tuning cubes, which confirms the presence of sand packages. On the eastern flanks of the Lower Cretaceous, the sweetness guide becomes 

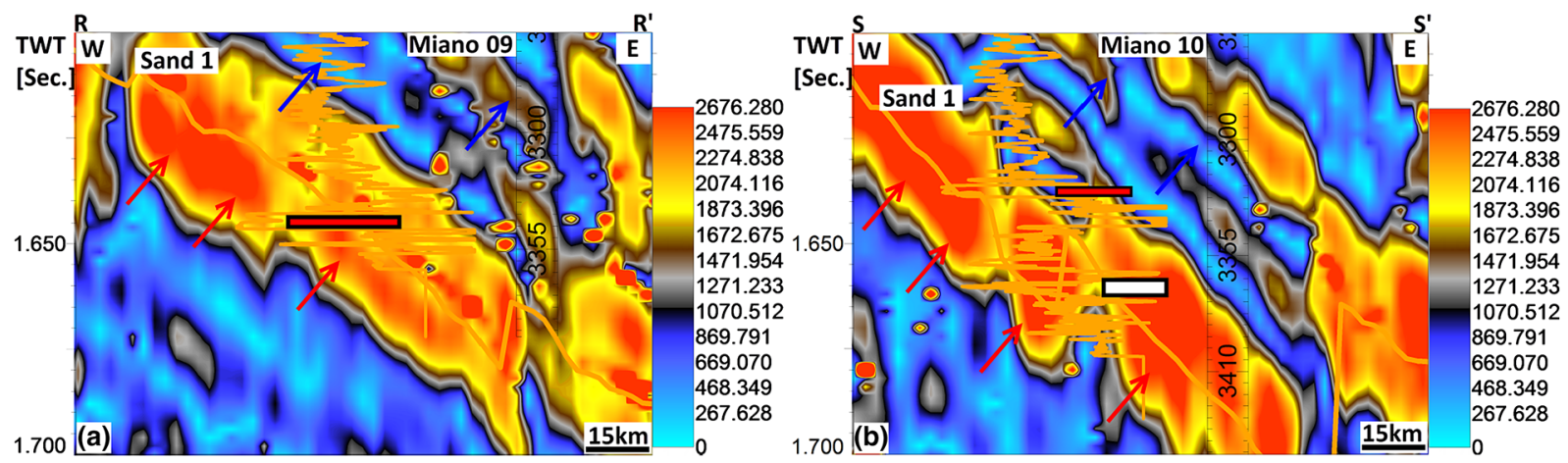

Figure 11. Sweetness sections with GR logs (golden curve) are overlain, (a) Miano 09 and (b) Miano 10, showing the productive (red arrows) non-productive (blue arrows) zone. The barrier bars are shown by a white horizontal bar, while the incised-valley fills are represented by a red horizon bar.

diminished, which affirms the occurrence of shale out zone, and provides the lateral seal for the incised-valley petroleum system (Naseer and Asim 2017a). A future gas prospect (red rectangle) is identified on the proximal side, which provides excellent clues for future gas exploration. The down dip conformance of gas-bearing strata along the faults F-A, F-B and F-C, validates this gas prospect. This zone is present exactly along the reservoir sands, which are delineated in the $22 \mathrm{~Hz}$ tuning cube of CWT (figure 9a). However, the low sweetness amplitudes show thinner (shale out) strata on the eastern flank (distal zone) of the Miano gas field, which provides the lateral seal for this gas prospect (Krois et al. 1998; Naseer and Asim 2017a). Consequently, drilling between the faults F-A and F-C on the western side of the Miano gas field, the identified prospect can improve the development of the Sand 1 reservoir.

\subsection{Comparative analyses between full spectrum and $C W T$ attributes}

Based on the horizon slice analyses of various band limited and CWT attributes (figures 6, 8, and 9), it is evident that the seismic amplitude, RAI, shows some clues about the reservoir architecture with band limitations (figures 6 and 8). However, the CWT completely resolved the thin beds of potential barrier bar sands and the dominant fault system within the complete reservoir zone. Therefore, CWT provides authentic interpretation of confirming the presence of lithology and the fracture network, which cannot be achieved using the full spectrum seismic attributes analyses (figures 6 and 8).

\subsection{Hydrocarbon detection}

Sweetness is the amplitude-based attribute, which is beneficial for imaging and discriminating the conventional and unconventional reservoirs such as the clastic channel sand, and hence, is considered as a hydrocarbon indicator (Radovich and Oliveros 1998; Tayyab and Asim 2017; Naseer and Asim 2017b). The low sweetness magnitudes (green arrows) are seen above the Sand 1 (figure 11). Therefore, these non-porous sediments, and hence, these transgressed shoreface clastics are inferred as the seal formation (Krois et al. 1998). The thick sand with blocky and coarsening upward GR expressions approves the presence of the incisedvalley fills and the barrier bars (figure 11) (Rider 1986; Naseer and Asim 2017a). These observations may be more obvious around $1650 \mathrm{~ms}$, where the high sweetness magnitudes (red arrows) are observed (figure 11a and b).

\subsubsection{Discriminating the fluvial barrier bar and incised-valley fills reservoir sands}

Based on the sweetness amplitude strength; the shallow zone surrounded by Miano 05 and Miano 06 shows the low-sweetness amplitudes, and so, are deduced as the secondary reservoirs (figures 7 and 11). But, the barrier bars and incised-valley fills show strong sweetness amplitudes, are hence, these deposits are inferred as the dominant gasbearing sand deposits (figure 11a and b) (Krois et al. 1998; Naseer and Asim 2017a). It is consistent with the high-frequency attenuation and the highest net to gross $(\mathrm{N} / \mathrm{G})$ distribution of reservoir facies and, where the barrier bar is inferred as the gas-bearing strata (figures 13 and 14). Hence, this zone might be inferred as the gas-bearing and 

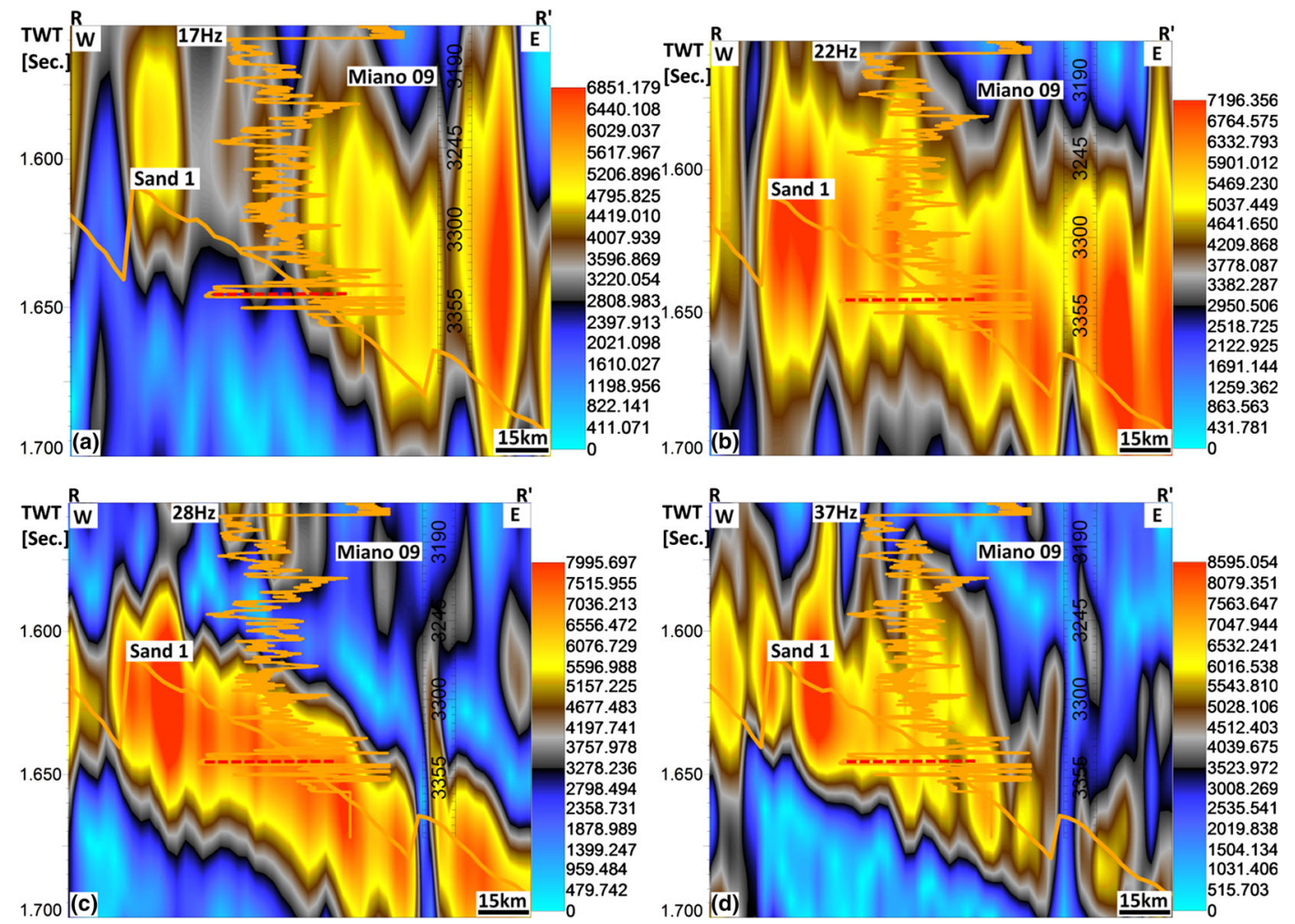

Figure 12. Spectrally decomposed seismic amplitude data into frequency contents. (a) $17 \mathrm{~Hz}$, (b) $22 \mathrm{~Hz},(\mathbf{c}) 28 \mathrm{~Hz}$, and (d) $37 \mathrm{~Hz}$ with GR log (orange curve) is overlain, showing the location of sand-filled valley (red dotted horizontal lines).

Table 2. The amplitudes used for the detection of the hydrocarbons.

\begin{tabular}{lcc}
\hline $\begin{array}{l}\text { Sl. } \\
\text { no. }\end{array}$ & $\begin{array}{c}\text { Frequencies } \\
(\mathrm{Hz})\end{array}$ & $\begin{array}{c}\text { Amplitudes } \\
(\mathrm{dB})\end{array}$ \\
\hline 1. & 17 & 4050 \\
2. & 22 & 2750 \\
3. & 28 & 1078 \\
4. & 37 & 569 \\
\hline
\end{tabular}

high N/G-bearing sands. Therefore, these sands are promising for future well locations. Since the deeper productive zones show the dominance of barrier bars and the sand fills within the incisedvalley system, the Lower Cretaceous zone of Goru Formation is interpreted as the barrier bars, which are the gas producers from medium to coarsegrained sands for the last two decades (Naseer and Asim 2017a). Table 1 correlates the gas status from Miano 09 and Miano 10, and therefore, the identified gas prospect can be productive for future exploration.

\section{$5.8 C W T$ iso-frequency amplitude analysis}

The hydrocarbon reservoirs are highly compartmentalized within the NNW-SSE oriented faults and sandwiched between the shales (Naseer and Asim 2017b). Therefore, to detect the reservoir beds within these scenarios using the conventional seismic data is a challenge for exploration. The CWT is executed for the accurate determination of reservoir beds. The conventional seismic amplitudes are decomposed into its constituent frequency components to detect the thin beds and thickness variation within the reservoir sands. For determining the sand beds of various thicknesses, four iso-frequency volumes of $17,22,28$, and $37 \mathrm{~Hz}$ are selected. After constraining the depths within the zone of interest, thick and thin barrier bars reservoir beds (the red dotted horizontal lines) are detected (figure 12). Since the blocky GR log expressions are indicators of incisedvalley sand fills, the thick beds demonstrate the bright amplitudes at low frequencies (figure 12a and $\mathrm{b}$ ). This energy boost in the sand package under the proven petroleum reservoir is declared as the gas-bearing sand lens, which is modeled in figure 16. Additionally, the reservoir facies modeling in the previous research project corroborates these observations (Naseer and Asim 2017a). On the other hand, the thin beds show the bright amplitudes at higher frequencies (figure 12c and d). 

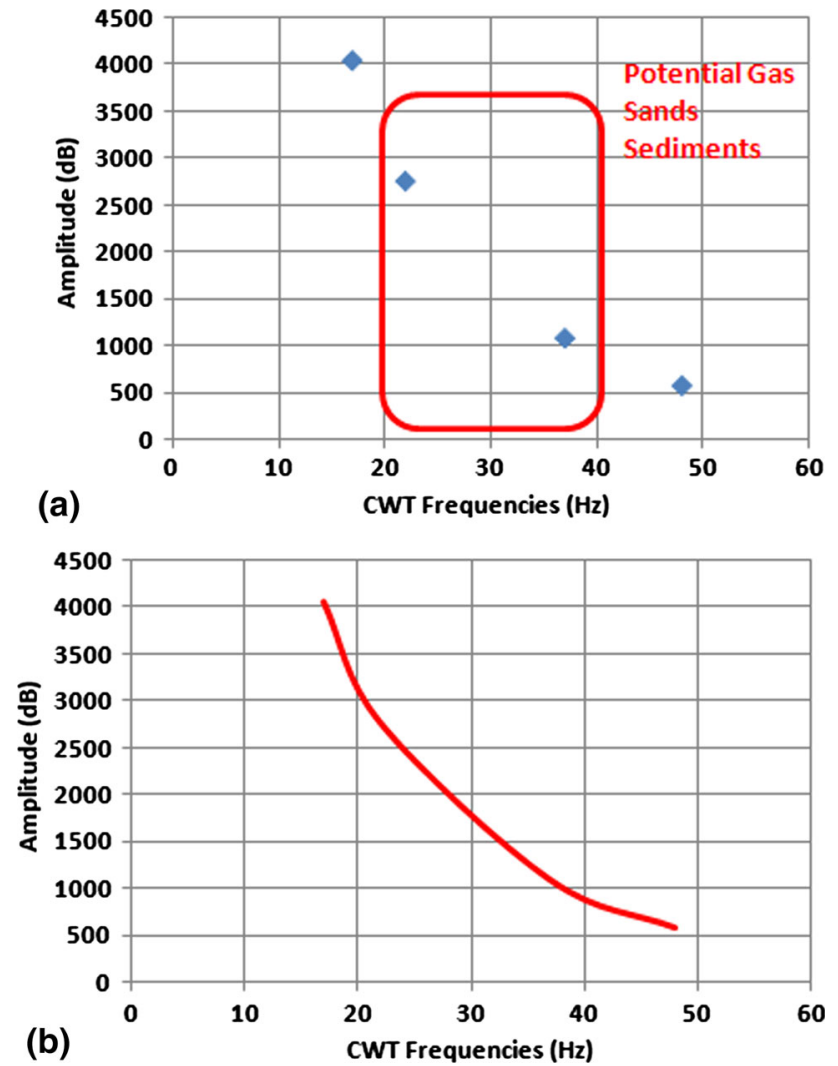

Figure 13. Plot between the CWT frequencies and amplitudes, showing the attenuation response of gas-bearing barrier bar coarse sands below the Sand 1 event. (a) Digital and (b) analogue display.

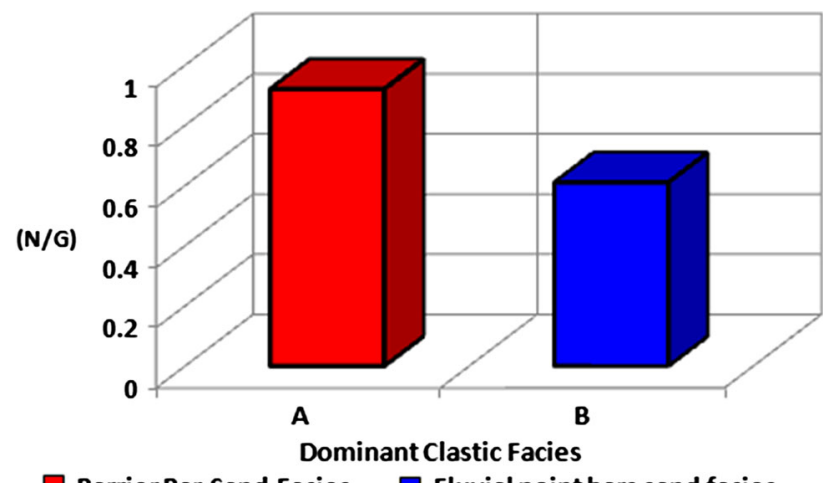

Figure 14. Plot between the reservoir facie and $N / G$, showing the leading reservoir facies.

\subsection{CWT amplitudes for calibration of gas-bearing barrier bars}

It is significant to analyze the amplitude attenuation to identify the gas-bearing zone (Naseer and Asim 2017b). For achieving the accurate reservoir characterization, a sand body $26 \mathrm{~m}$ thickness greater than the tuning thickness, i.e., $23 \mathrm{~m}$ of the reservoir unit is selected from Miano 05. Table 2 shows the computed amplitudes and frequencies within the point bars sand facies. These amplitudes are worked out from the surrounding wells. These amplitudes are cross-plotted against the four frequencies of $17,22,37$, and $48 \mathrm{~Hz}$ (figure 13).

Figure 13 shows the cross plot between the CWT amplitudes and frequencies for detecting the possible hydrocarbon-bearing sediments. At a low frequency of $17 \mathrm{~Hz}$, reservoir energy increases to $4050 \mathrm{~dB}$. Most of the sands proved to be tight or produced water with some gas. B sand produces gas at a high rate (Krois et al. 1998). Hence, this high energy may be attributed to the presence of gas sands (Naseer and Asim 2017a). The reservoir experiences faster amplitude attenuation (2750 and $1078 \mathrm{~dB}$ ) at higher frequencies of 22 and $37 \mathrm{~Hz}$, which confirm the gas-bearing sediments within the Sand-1 zone (figure 13) (Naseer and Asim 2017a).

\subsection{Reservoir facies analysis}

It is imperative to observe the relationship between the sandstone and non-sandstone portion within the channel fills (Miall 2006; Naseer and Asim 2017a) for discrimination of the leading reservoir facies. Two achieve this stratigraphic reservoir characterization goal, two sand bodies with a thickness of 28 and $32 \mathrm{~m}$ respectively, are selected, and the net to gross ratio is cautiously controlled out from Miano 07 (figure 14). Table 3 shows the N/G of various sand facies.

Figure 14 shows the N/G distribution for the dominant reservoir facies, i.e., the barrier and point bar. The bar graph shows that the barrier bar acts as the primary reservoir with $\mathrm{N} / \mathrm{G}$ of 0.96 , while the fluvial point bars serve as the secondary reservoir with $\mathrm{N} / \mathrm{G}$ of 0.61 . The barrier bars are inferred as the dominant gas-bearing facies within Miano gas field (Naseer and Asim 2017a). Consequently, these fluvial barrier bars may be more helpful for future exploration as compared to the point bars (Naseer and Asim 2017a). Therefore, based on this $\mathrm{N} / \mathrm{G}$ analysis, a gas-bearing barrier bar lens is selected within the incised-valley to resolve the sand fills using the acoustic impedance wedge model, and to discriminate the productive and non-productive parts for successful exploitation of undiscovered prospect, where the thick fluvial sand facie, i.e., barrier bar is resolved from the non-porous shales (figure 16). 
Table 3. $N / G$ for the leading reservoir facies.

\begin{tabular}{llllc}
\hline Sl. no. & Well name & Reservoir facies & N/G & $\begin{array}{c}\text { Depth } \\
(\mathrm{m})\end{array}$ \\
\hline 1. & Miano 07 & Fluvial point bars & 0.61 & $2142-2964$ \\
2. & Miano 07 & Barrier bars & 0.96 & $2365-3328$ \\
\hline
\end{tabular}

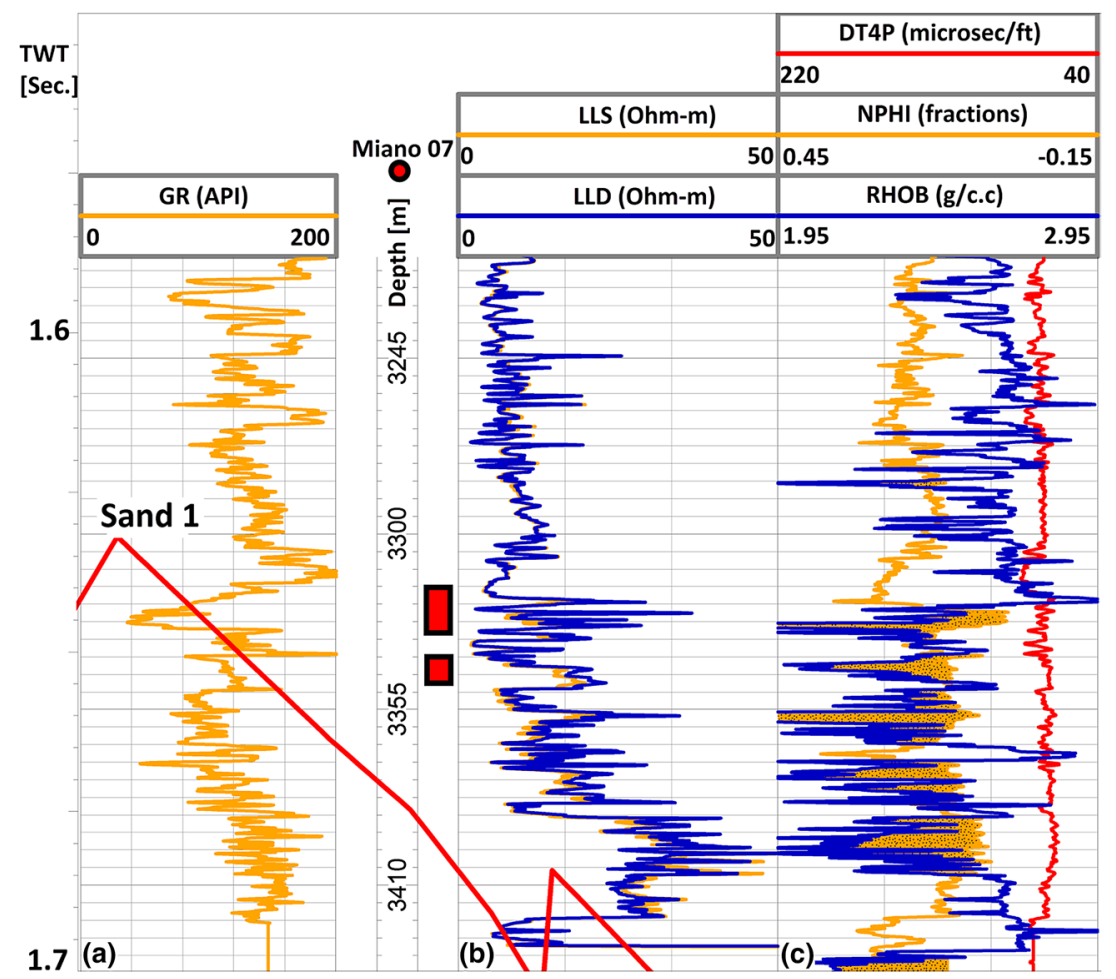

Figure 15. Petrophysical analysis of Miano 07 with panels (a) GR (API), (b) LLD (Ohm-m) and LLS (Ohm-m) and (c) RHOB (g/c.c), NPHI (fraction), DT4P (micro sec/ft.), showing the gas pay sands (red bars). The cut-off for clean sands is 60 (API).

\subsection{Petrophysical reservoir characterization}

Figure 15 shows the petrophysical characterization of Miano 05 to discriminate the possible reservoir fluids within the mapped sand bodies (figures 6-9). In order to identify the gas pay sands within the heterogeneous fluvial system, the first and crucial step is to recognize the lithology of the reservoir (Hynes 1991). To achieve this purpose, the GR $\log$ is the best borehole tool for the recognition of dominant reservoir lithology. Panel (a) shows the GR log, which is processed within the zone of interest. Gamma-ray tools measure the natural radioactivity which is created in the rock. The components which deliver gamma radiation of hugeness in common sedimentary rocks are potassium, thorium, and uranium. The relative commitment of the aggregate recorded radiation is the end goal that $1 \mathrm{ppm}$ uranium compares to $3.65 \mathrm{ppm}$ thorium and $2.70 \%$ potassium. Shale regularly contains a large portion of these components and the gammaray count of shales is quite often higher than that of sandstones (Landrø 2011). Therefore, the zone comprising of high values of GR are interpreted as the shales, while the low values are interpreted as the sand. The gas-bearing strait is the sandstone reservoir (Naseer and Asim 2017b). Therefore, these low values of GR are inferred as the sandstone. The cut-off for the clean sand is $<60$ API. The second step in the petrophysical reservoir characterization is to identify the fluid within the reservoir formations. To achieve this objective, the LLD and LLS is the true fluid indicator. Since resistivity tools measure the current conductivity 
of the formation after passing the current into the stratigraphic layer within the borehole, various fluids, i.e., oil, and chiefly gas, will greatly increase the resistivity (Landrø 2011). Water is more conductive to current, low values of resistivity are interpreted as the water-bearing/brine strata. But, the Low values of conductivity shows the high resistivity. Since the oil/gas bearing zones are less conductive to current, are interpreted to show high resistivity values. Panel (b) diligently correlates these observations, where the pay zones are shown by the red vertical bars. The third most important hydrocarbon indicator is the NPHI and RHOB crossover. Panel (c) shows the track, where the RHOB, NPHI, and DT4P logs are shown. The neutron-porosity tool measures the intensity of the hydrogen index within the reservoir formation. This tool is used to measure clay content. The shale has high clay content and water has high values of hydrogen index as compared to the oil/gas-bearing strait. Gas experiences low-density (Landrø 2011). Therefore, the zones comprising of low NPHI values having crossover with density log, affirms the presence of hydrocarbon-bearing zone (Landrø 2011). Moreover, DT4P log measures the travel time that a wave travels within the reservoir formation, and in terms of hydrocarbon indications, its shows the porosity (Landrø 2011). The hydrocarbon-bearing zone experiences low velocity (high-porosity), while the shale experiences high velocity (low-porosity) (Naseer and Asim 2017a). High values of DT4P are interpreted as the low velocity, and hence high porosity reservoir zone. Therefore, this crossover between the RHOB and NPHI in conjunction with the high DT4P values provides optimistic implications for the presence of gas-bearing strata tools confirms the gas-bearing sands. These pay sands are consistent with the barrier bar and incisedvalley sand-filled packages, which are mapped on the $22 \mathrm{~Hz}$ and $28 \mathrm{~Hz}$ amplitude slice (figure 9).

\subsection{Seismic resolution}

With a specific end goal to outline the stratigraphic events, the seismic resolution has an essential influence to determine the thin sands (Chopra et al. 2006). There are two sorts of seismic resolution; which includes the vertical and horizontal resolution. Vertical determination manages the partition of two vertical seismic reflections. On the other hand, the vertical resolution denotes the two along the side heterogeneous stratigraphic beds. Be that as it may, the present investigation relates to the vertical determination. For this situation, we have utilized the seismic resolution for the choice of the sand bodies, for example, the fluvial barrier bar sands towards certifying the present seismic characteristics examination.

According to figure 3(b), the reservoir interval experience maximum amplitude between $\sim 9$ and $60 \mathrm{~Hz}$. Approximately, $22 \mathrm{~Hz}$ has opted as the peak frequency and the interval velocity $v$ of $2026 \mathrm{~m} / \mathrm{s}$ was taken within the reservoir zone. From the relation of frequency $f$ with velocity $v$ and wavelength $\lambda$, we have

$$
\begin{aligned}
V & =f \lambda . \\
\lambda & =23 \mathrm{~m} .
\end{aligned}
$$

Thus, from the above analysis, the thickness of the reservoir zone is approximately $\sim 23 \mathrm{~m}$. Therefore, it is accomplished that the minimum thickness required to detect the thin beds should be equal or greater than the tuning thickness of the reservoir that is $\sim 23 \mathrm{~m}$. The seismic wedge model is made to corroborate the presence of gas-bearing point bar sand deposits (figure 16).

It is very imperative to emphasize that the predicted and resolved tuning thickness are same , i.e., $23 \mathrm{~m}$. These outcomes are briefly described and discussed during the wedge modeling of incised-valley sand-filled wedge system (figure 16).

\subsubsection{Seismic forward modeling}

The most considerable geologic sign is the outside outline of the reservoir, distinctive via seals or stream barriers, which oblige the movement of oil and gas, developing a lithology trap. The buoyancy force produced by the unstable density between the water and hydrocarbons initiates migration. Migration will terminate, a hydrocarbon reservoir will come into existence, exclusively where the hydrocarbons happen to form a trap (Petrowiki 2015).

The present case deals with the synthetic wedge modeling, which is made to outline the reservoir and seal elements of the petroleum system (figure 16). Table 4 shows the various constraints used for generating the wedge model. This model is selected within the zone exactly where, seismic attributes, detection of thin beds, and amplitude attenuation analysis is performed (figures 6-13).

At first, the lithology distribution is made to characterize the prominent lithologies (figure 16a). Initial velocity model (IVM) is produced in the wake of explaining the constant velocity (figure 16b). It is better to use the wavelet 

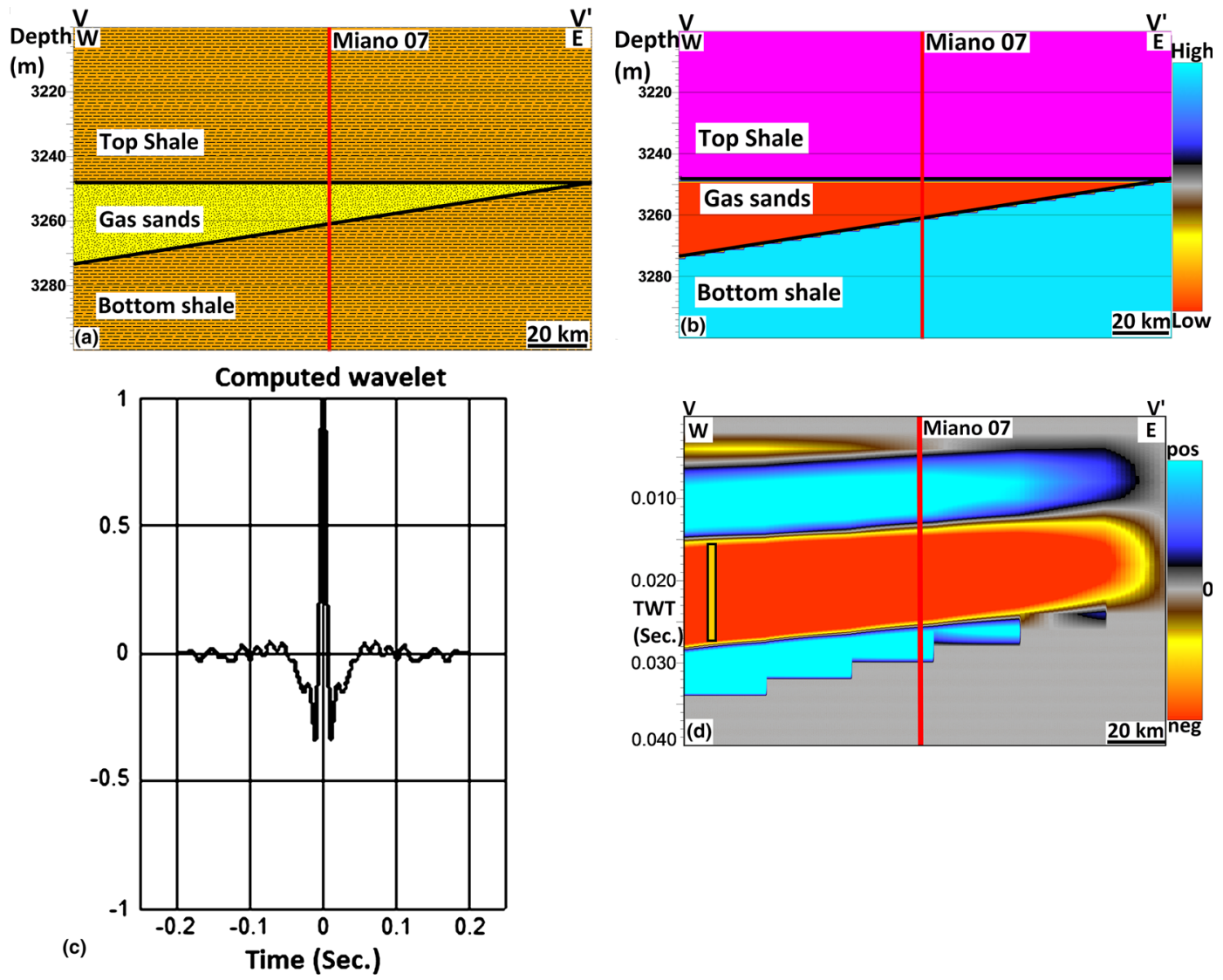

Figure 16. Schematic workflows applied to develop the seismic acoustic impedance wedge model within the reservoir zone. (a) Initial property dissemination model, (b) the initial velocity model after annotating the continuous velocity (m/sec), (c) seismic zero-phase wavelet extracted at Miano 07, and (d) the resulting acoustic impedance wedge model with colour coded to P-wave impedance, which resolves the low acoustic impedance (high-quality) thick gas-bearing barrier bar sand lens from the high acoustic impedance (low-quality) thin shale.

extracted based on the well log data (Naseer and Asim 2017b). Therefore, after extracting the zerophase seismic wavelet with 82 follows (figure 16c), the convolution of the (IVM) with the zero-phased seismic wavelet is performed, which demarcates the acoustic impedance wedge model (figure 16d). It is interesting to observe here that the velocity profile is not able to show the exact dimensions of the reservoir facie. However, when convolved with the wavelet extraction of the seismic data, it shows the excellently resolved sand package.

\subsubsection{Characterization of incised-valley wedge system}

The low acoustic impedance (AI) sand facie (orange vertical bar) is encased from top, lateral, and bottom high AI shales making an excellent stratigraphic trap. This low impedance sand wedge is exactly from the reservoir zone, where the barrier bar sands are delineated (figures 6 and 7 ). Since, the flat top with coarsening upward character of GR indicates fluvial channels sandstone bodies, they have their greatest permeability at the top of the barrier bar body (Rider 1986; AAPG 2016). The high permeability may provide a pathway to allow the upward hydrocarbon migration. It is in accordance with figure 9, where the thin and thick beds of the fluvial barrier bar reservoir is identified using the Iso-frequency seismic sections. Hence, the low impedance and high permeability sand package, is inferred as the gas-bearing point bars (figure 16d).

Also, it is interesting to observe that the thickness of this low impedance reservoir facie is $23 \mathrm{~m}$ with lateral distribution of $\sim 18 \mathrm{~km}$, and Miano 07 is drilled on the up dip side of the reservoir. It is noticeable that the up-dip part of the reservoir is present on the distal side (eastern part of the area). Hence, it provides optimistic evidence for the upward sealing geometry and downward hydrocarbon conformance. The oil and gas exploration companies are interested in the EW lateral fluctuations of reservoir facies within the Indus Basin (Kadri 1995). Therefore, this sand model 
Table 4. Physical constraints used for the wedge modeling.

\begin{tabular}{llcccc}
\hline Lithology & $\begin{array}{l}\text { Depth } \\
(\mathrm{m})\end{array}$ & $\begin{array}{l}\text { Velocity } \\
(\mathrm{m} / \mathrm{sec})\end{array}$ & $\begin{array}{l}\text { Density } \\
(\mathrm{g} / \mathrm{c} . \mathrm{c})\end{array}$ & $\begin{array}{c}\text { Acoustic impedance } \\
(\mathrm{m} / \mathrm{sec} \text { * } \mathrm{g} / \mathrm{c} . \mathrm{c})\end{array}$ & $\begin{array}{l}\text { Reservoir } \\
\text { quality }\end{array}$ \\
\hline Top shale & $3205-3248$ & 4665 & 2.638 & 12306 & Poor \\
Gas-bearing sands & $3249-3273$ & 4429 & 1.511 & 6692 & Excellent \\
Bottom shale & $3273-3283$ & 4655 & 2.617 & 12182 & Poor \\
\hline
\end{tabular}

provides implications for stratigraphic trap, which could have explored for assessing the overall depositional model for future field development. Table 1 correlates the gas status from Miano 07, and therefore, the recognized gas scenes can be fruitful in future exploration. Consequently, by considering these reservoir characteristics, it may be economically vibrant to drill a new well on the western part (orange bar) for delineating the undiscovered stratigraphic hydrocarbon reserves (figure 16d). The seismic resolution is in $100 \%$ match with the predicted one (equation 2). Therefore, the reservoir beds are at the tuning thickness, and the CWT can be successfully applied to delineate and predict the complete range of reservoir attributes; including the true lithology, thickness, and possible porosity effects with full assurance. This model also provide the feasibility approach to confirm the presence of thin-bedded and thickest gas-bearing reservoirs of incised-valley wedge system.

\subsection{Stratigraphic implications for future exploration}

In summary, various attributes are applied to delineate the productive reservoir sands within the complex fluvial depositional system. The $22 \mathrm{~Hz}$ amplitude tuning cube provides an excellent picture of stratigraphic reservoir characterization. On the other side, the seismic amplitude, coherency, and sweetness attributes could provide clues for the prospective sands (figures 6a, 7, and 8). The practical implication for fluvial reservoir characterization is that the fluvial point bar and barrier bars sands are considered as the potential stratigraphic traps (Galloway and Hobday 1996; Naseer and Asim 2017b). The CWT recognizes the thick and thin beds within an incised-valley filled with sands within the reservoir system (figure 12). The barrier bar sand modeled by the synthetic wedge modeling, which confirms the implications for stratigraphic exploration within the Miano gas field, Pakistan (figure 16). Therefore, based on these observations, these clastic packages could have explored by drilling the development wells on the western part within the Miano gas field, Pakistan.

\section{Conclusions}

An integrated study using the CWT and synthetic wedge modeling tools is analyzed to delineate the potential sands deposits. The present research is concluded as follows:

Coherency could provide the clue for barrier bar sands, but successfully delineated the edges of incised-valley system. NS, NE-SW, and NW$\mathrm{SE}$ oriented regional faults and discontinuities can be helpful for compartmentalizing the thick sands, which are distributed on the NE and NW regions.

Sweetness attribute in conjunction with GR log can be used as a lithology discriminator, i.e., the fluvial barrier and point bars, which are cataloged by NNW-SSE regional faults making an excellent stratigraphic/structural trapping configurations (Naseer and Asim 2017a).

Based on the seismic attributes analyses, the Upper Cretaceous sequence is dominated with fluvial sand-filled and point bars, while Lower Cretaceous one is influenced by the sand-filled barrier bars and incised-valley deposits (Naseer and Asim 2017a; Tayyab and Asim 2017).

The CWT discriminates the thick and thin beds of fluvial barrier bars. $22 \mathrm{~Hz}$ excellently delineates the prospective sands (barriers bars), dense fracture network, and the architectural configurations within the incised-valley reservoir system. Amplitude attenuation between the 22 and 37$\mathrm{Hz}$ frequencies corroborates the hydrocarbons and suggested the bright signatures for extracting and exploitation of economically vibrant stratigraphic plays in the study area. Therefore, CWT can be used as a comprehensive tool for characterization of incised-valley sand system for future prospect delineation.

$\mathrm{N} / \mathrm{G}$ reveals the barrier and point bars as the leading clastics, which constitute the major hydrocarbon zones. 
The acoustic impedance wedge model resolves the gas-bearing barrier bars sand having thickness of $23 \mathrm{~m}$ and lateral extent of $18 \mathrm{~km}$, which are encased within the thin shales, confirms the stratigraphic prospects. Moreover, this pinch out model also proves that the Miano gas field has a true vertical resolution of $23 \mathrm{~m}$. The wedge model made a $100 \%$ correlation of the predicted $(\sim 23 \mathrm{~m})$ vertical resolution, as shown by equation (2), with the observed $(\sim 23 \mathrm{~m})$ resolved beds within the incised-valley sand-filled barrier bars, which proves the fruitful direct hydrocarbon indicators (DHIs). Therefore, this sand bed is interpreted as the gas-bearing sand-filled reservoir within the incised-valley. The wedge should be executed for delineation and demarcation of sandfilled and shale-filled reservoirs, for accurate stratigraphic exploration. Hence, it is proved that the acoustic impedance modeling for pinch out stratigraphic regimes can be successfully applied for resolution concerns, DHI, and delineation of complete petroleum system within the stratigraphic regimes of varied deposition systems.

\section{Acknowledgements}

Authors are thankful to the Directorate General of Petroleum Concession (DGPC) for giving the permission to publish this paper. We are also thankful to Department of Earth Sciences, Quaid-I-Azam University and LMKR for providing the research data. We are highly grateful to the respected reviewers for their positive criticism, which made our manuscript in an excellent form. Seismic-microtechnology (SMT) Kingdom platform support is highly acknowledged during this research project.

\section{References}

Ahmed N, Paul F, Sturrock S, Mahmood T and Ibrahim M 2004 Sequence stratigraphy as a predictive tool in Lower Guru Fairway, Lower and Middle Indus Platform, Pakistan; Pakistan Association of Petroleum Geoscientist, Annual Technical Conference, October 8-9, pp. 17-18.

Ahmed W, Azeem A, Abid M F, Rasheed A and Aziz K 2013 Mesozoic structural architecture of the Middle Indus Basin, Pakistan - controls and implications; Pakistan Association of Petroleum Geoscientist/Society of Petroleum Engineers Annual Technical Conference, Islamabad, Pakistan, pp. 1-113.

Asim S, Zhu P, Naseer M T, Abbasi S A and Rehman M 2016 An integrated study to analyze the reservoir potential using stochastic inversion, model based inversion and petrophysical analysis: A case study from the Southern Indus Basin, Pakistan; J. Earth Sci.,https://doi.org/10. 1007/s12583-016-0903-1.

Castagna J P 2006 Comparison of spectral decomposition methods; First Break 24 75-79.

Castagna J, Sun S and Siegfried R 2003 Instantaneous spectral analysis: Detection of low-frequency shadows associated with hydrocarbons; The Lead Edge 22 120127, https://doi.org/10.1190/1.1559038/.

Chen G, Matteucci G, Fahmi B and Finn C 2008 Spectral decomposition response to reservoir fluids from a deep water West Africa reservoir; Geophysics $\mathbf{7 3}$ C23-C30.

Chopra S and Marfurt K 2005 SEG 75th Anniversary, Seismic attributes - a historical perspective; Geophysics $\mathbf{7 0}$ $3-28$.

Chopra S and Marfurt K J 2006 Seismic attribute mapping of structure and stratigraphy; Society of Exploration Geophysics.

Chopra S, Misra S and Marfurt K 2011 Coherence and curvature attributes on preconditioned seismic data; The Lead Edge 30(4) 386-393.

Evans W S 1996 Technologies for multidisciplinary reservoir characterization; J. Pet. Tech. 48(1) 24-25.

Farfour M, Yoon W J and Jo Y 2012 Spectral decomposition in illuminating thin sand channel reservoir, Alberta, Canada; Canad. J. Pure Appl. Sci. 6(2) 19811990 .

Galloway W E and Hobday D K 1996 Terrigenous clastic depositional systems. Applications to fossil fuel and groundwater resources; Springer-Verlag, pp. 400-417.

Goloshubin G, Vanschuyver C, Korneev V, Silin D and Vingalov V 2006 Reservoir imaging using low frequencies of seismic reflections; The Lead Edge 25 527-531.

Hynes N J 1991 Dictionary of petroleum exploration, drilling, and production; Tulsa, Oklahoma: PennWell.

Kadri I B 1995 Petroleum geology of Pakistan; Graphic Publishers, Karachi, pp. 93-108.

Krois P, Mahmood T and Milan G 1998 Miano field, Pakistan, a case history of model driven exploration; Proceedings of the Pakistan Petroleum Convention, Pakistan Association of Petroleum Geologists, Islamabad, pp. $111-131$.

Landrø M 2011 Petroleum geoscience: From sedimentary environments to rock physics; Springer-Verlag, Berlin Heidelberg, Germany, pp. 360-373.

Laughlin K, Garossino P and Partyka G 2003 Spectral decomposition for seismic stratigraphic patterns; Search and Discovery, article 40096, 4p.

Lynch S and Lines L 2004 Combined attributes displays; 72nd Annual International Meeting, SEG, expanded abstracts, pp. 1953-1956.

Miall A D 2006 The geology of fluvial deposits sedimentary facies, basin analysis, and petroleum geology; Springer, pp. 340-342.

Naseer M T and Asim S 2017a Continuous wavelet transforms of spectral decomposition analyses for fluvial reservoir characterization of Miano Gas Field, Indus Platform, Pakistan; Arab. J. Geosci. 10(210), https://doi.org/10. 1007/s12517-017-2920-5.

Naseer M T and Asim S 2017b Detection of cretaceous incised-valley shale for resource play, Miano 
gas field, SW Pakistan: Spectral decomposition using continuous wavelet transform; J. Asian Earth. Sci. 147 $358-377$.

Naseer M T, Asim S and Ahmed S 2015 Spectral decomposition and seismic attributes for clastic reservoir analysis of Miano Gas Field, Southern Indus Basin, Pakistan; Sindh Univ. Res. J. (Sci. Ser.) 47(1) 35-40.

Partyka G, Gridley J and Lopez J 1999 Interpretational applications of spectral decomposition in reservoir characterization; The Lead Edge 18(3) 353-360.

Puryear ChI and Castagna J P 2008 Layer-thickness determination and stratigraphic interpretation using spectral inversion: Theory and application; Geophysics $\mathbf{7 3 ( 2 )}$ $37-48$.

Radovich B J and Oliveros R B 1998 3-D sequence interpretation of seismic instantaneous attributes from the Gorgon field; The Lead Edge 17 1286-1293.

Rider M H 1986 The geological interpretation of well logs; Blackie, New York.

Sahu S and Saha D 2014 Geomorphologic, stratigraphic and sedimentologic evidences of tectonic activity in SoneGanga alluvial tract in Middle Ganga Plain, India; $J$. Earth Syst. Sci. 123(6) 1335-1347.
Singavarapu A, Singh S K, Alvarez M, Al-Owihan H, AlAjmi A, and Al-Rashidi S 2014 Seismic attributes and wave form classification: An emerging tool for exploration of shallow oil play, Kuwait. In: SEG Technical Program Expanded Abstracts 2014 (pp. 1538-1542). Society of Exploration Geophysicists.

Sinha S, Routh P S, Anne P D and Castagna J P 2005 Spectral decomposition of seismic data with continuouswavelet transform; Geophysics 70 19-25.

Tayyab M N and Asim S 2017 Application of spectral decomposition for the detection of fluvial sand reservoirs, Indus Basin, SW Pakistan; Geosci. J. 21(4) 595-605.

Tayyab M N, Asim S, Siddiqui M M, Naeem M, Solange S H and Babar F K 2017 Seismic attributes' application to evaluate the Goru clastics of Indus Basin, Pakistan; Arab. J. Geosci. 10(7) 158.

Xiao Y, Zhou G and Yang F S 2016 2D numerical modeling of meandering channel formation; J. Earth Syst. Sci. 125 (2) 251-267.

http://petrowiki.org/2015/Reservoir_geology

http://wiki.aapg.org/Lithofacies_and_environmental_analy sis_of_clastic_depositional_systems; 2016.

Corresponding editor: N V CHALAPATHI RAO 